\title{
Horizontal Wells: Applications, Considerations, and Case Histories
}

\author{
Adnan Zalzala \\ Husky Energy Inc., Calgary, AB, Canada
}

\section{$\underline{\text { Abstract }}$}

\section{This paper discusses}

many aspects of the application of horizontal wells for field development, starting with the basic question of why to opt to this technology. The different considerations to be taken into account when dealing with the technology are reviewed, including some inherent downsides like higher cost and operational complications. The main emphasis, however, is placed on practical reservoir engineering aspects, including well planning and performance, and the handling of horizontal wells in specific technical applications like well test analysis and numerical modeling.
The theoretical basis and pertinent differences in physics and flow regimes around vertical and horizontal wells are discussed in the context, together with the inherent practical implications.

Case histories and examples are presented for several successful applications worldwide that the author was involved in. In one case, a medium size field offshore Canada was developed with waterflood utilizing very few horizontal producers, with a set of horizontal and vertical water injectors. Detailed planning and intensive modeling, carried out by a team of engineers and geoscientists, led to a remarkably 
successful field development. In another case, few horizontals were used among many directional wells to develop a Mediterranean oil reservoir under aquifer and gas cap drives in an attempt to reduce coning problems, raising an opportunity to compare the long term performance of different geometry wells.

A brief description is also presented to some advanced techniques and special cases of implementing horizontal wells such as thermal recovery (SteamAssisted-Gravity-Drainage, or SAGD Process), multi-lateral wells, and multi-fractured wells, with discussion on these applications. Under favorable conditions, horizontal wells can also be used as an Improved Oil Recovery (IOR) tool in mature fields, an application that became very common in many super giant fields in the Arabian Gulf Area.

\section{$\underline{\text { Introduction }}$}

Drilling horizontal wells for field development has gained a wide acceptance in the oil and gas industry, becoming a standard tool when the geology and reservoir conditions are appropriate. In the past 25 years, the technology has developed from laterals of only tens of meters in length to present day horizontals of several kilometers. While initial use was mainly as an offshore application to reduce the number of wellbores, onshore use is now quite common for a variety of reasons. In North America, more horizontals are being drilled over the past few years than other type of wells. With the wider implementation, the industry has developed many useful tools that the reservoir and field development engineers can use to tackle the different aspects related to the performance, data 
acquisition, and data analyses of these wells, in a scientifically robust manner. On the other hand, few problems were revealed that are still to be resolved.

With the ambitious plans to develop the Iraqi oil fields on a fast pace and to multiply the country's current oil and gas production, the need to apply modern and advanced technologies is manifested as a prime requirement. It is not intended here to specifically discuss the application of horizontal wells for Iraqi fields, but it is safe to state that many geologic and reservoir aspects of these fields could call for the implementation of the technology as a convenient approach. Examples of these are low permeability reservoirs, primary gas cap reservoirs, and small pay zones. The giant mature fields' implementation of horizontal wells is deemed vital as a tool to enhance the ultimate recovery under primary and secondary schemes.

\section{Basic Considerations}

Why Horizontal Well: the primary reason to drill horizontal wells (HWS A list of all abbreviations is given at the end of the paper) is to increase the productivity per wellbore, reducing the well count for the same field throughput. This objective is achieved via the larger reservoir exposure area in the horizontal section than that in a vertical one, the latter being limited by the pay zone thickness. Ordinarily, the areal extension of any reservoir is many times bigger than the pay thickness. The smaller the thickness, the higher is this ratio. For example, comparing a hole fully penetrating vertically in 
a $20 \mathrm{~m}$ pay formation, with one drilled horizontally for $500 \mathrm{~m}$, the

ratio is 25 times. As productivity is directly proportional to the flow capacity, it is intuitive to expect the horizontal well to have better productivity.
More specifically, and in simplest formulation, the steady state productivity Index of a conventional (vertical) undamaged well is expressed as:

$$
\mathrm{JV}=\mathrm{Kh} . \mathrm{H} /(270.7 \cdot \mu \cdot \mathrm{B} \cdot[\ln (\mathrm{re} / \mathrm{rw})-0.75])
$$

where $\mathrm{Kh}$ is the horizontal formation permeability and $\mathrm{H}$ is the pay thickness. For a corresponding HW of length Lh, Joshi(1) derived the following formula:

$\mathrm{Jh}=\mathrm{Kh} \cdot \mathrm{H}^{\prime} /\left\{270 \cdot 7 \cdot \mu \cdot \mathrm{B} \cdot\left[\ln [(\mathrm{A}+\sqrt{ }(\mathrm{A} 2-\mathrm{b} 2)) / \mathrm{b}]+\left(\mathrm{H}^{\prime} / \mathrm{Lh}\right) \cdot \ln [\mathrm{H} /(2 . \mathrm{rw})]\right]\right\}$

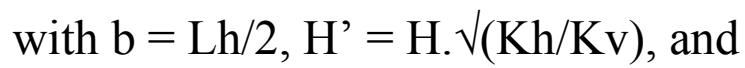

$$
\mathrm{A}=\mathrm{b} .\{0.5+\sqrt{ }[0.25+(\mathrm{re} / \mathrm{b}) 4]\} 0.5
$$

The main factors controlling three, the horizontal length can be productivity calculations for increased to enhance productivity. vertical wells (VWS) are permeability, pay thickness, and fluid viscosity. For HWS, at least one more parameter plays a prime role, i.e. the lateral length. While there is no control on the first

Generally speaking, the most common factor for low productivity is tight formation rocks. However, the extra high viscosity is the main reason for the reduced productivity in heavy oil 
reservoirs. For this latter situation, HWS were also successfully used to produce at commercial rates under primary depletion schemes (sometimes called Cold Production).

Flow Directions: in the example above, the ratio of length to pay thickness was 25. Practically, it should not be expected to have the same ratio of improvement in productivity on HWS. The reason is related to the direction of flow and the difference in flow patterns around the well. The dominant pattern in a conventional well is radial flow in the areal plane, along the horizontal permeability, if the wellbore is perpendicular to the bedding plane. In a HW, flow should take place, at least partially, in a vertical plane

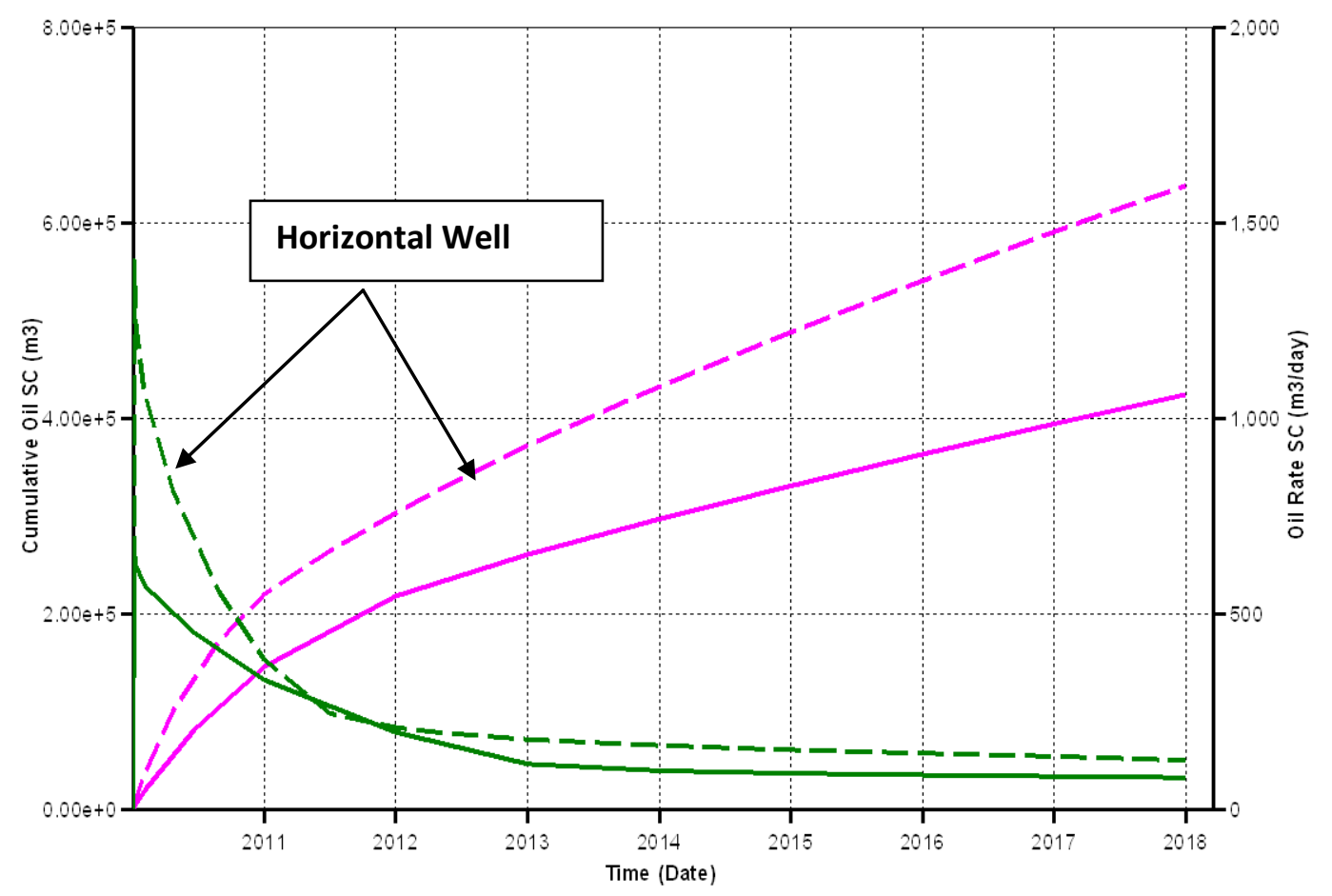

Fig.(1) Oil Production Comparison in a Horizontal and Vertical Wells 


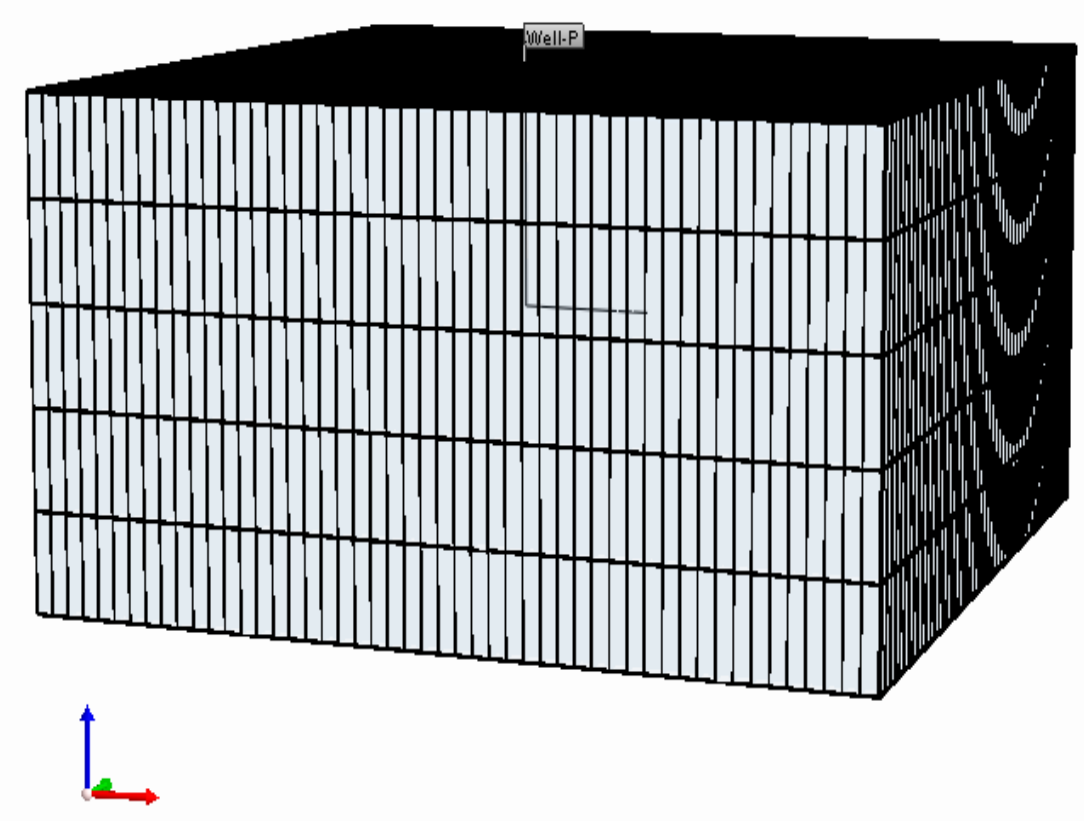

Fig.(2) A Box Numerical Model with a Horizontal Well

around the wellbore, along the smaller vertical permeability. It is usually accepted for $\mathrm{Kv} / \mathrm{Kh}$ ratio to be in the order of 0.1 , therefore the improvement in the example above is only about 3.5 times. Simulated results with a "Box Model" using the well dimensions above in a 100 $\mathrm{mD}$ pool shows a $\mathrm{HW}$ to produce at a higher rate, recovering $50 \%$ more oil over a period of 8 years, than a fully penetrating vertical well (Figs. 1,2).

Vertical Permeability Impact:

The discussion above and the productivity equation indicate the importance of vertical permeability (in the plane perpendicular to wellbore axis) to the flow capacity of HWS, contrary to VWS whereas this parameter has essentially no role, except for 
specific cases like partial completion. If the vertical permeability is small, or if thin shale streaks are reducing the overall vertical conductivity in the reservoir, the productivity could be seriously impacted. In fact, HWS are not recommended for reservoirs with very small vertical conductivity. Fig.(3) shows the impact of vertical permeability on productivity, derived from Joshi's formula above.

\section{A Horizontal Well is Never} Horizontal: due to inherent geological and mechanical factors, what is termed 'horizontal' well is in reality neither straight nor flat in trajectory. It is a frequently a sinusoidal hole with many undulations that may increase or decrease in number according to the formation lithology and drilling environment, and the adopted directional control.
An actual profile for few HWS drilled to develop an offshore field (Case History 1 below) is shown in Fig.(4). In addition to the undulations, they are usually not flat. With the development of geosteering technology, the hole is directed to follow the layerization and/or the favorable petrophysical trend, and it is not unusual to have laterals that rise up on the toe side by many meters.

An important practical side related to the undulation is the impact on well performance. With water and sediments production, the 'sumps' along the lateral will form an accumulation spot that could plug, partially or completely, fluid flow in the hole. It may also form an obstacle against any logging or coiled tubing operations during the well life.

\section{Limitations and Drawbacks:}

with all the merits of HWS, they 
have their downsides as well. These can fall under few categories:

- Cost: drilling and completing a HW may cost up to two times that of a VW, depending on the length, depth, and completion equipments and technique, among other factors. While the drilling aspects are not addressed here, some of the relevant completion aspects will be discussed under the Case Histories and examples.

- Operational Complications: in general, wellbore operations are more difficult and sometimes not feasible in horizontal wells. Running wireline $\operatorname{logs}$ can only be performed by mounting tools

- heterogeneity, wellbore bridging, perforation plugging, and multi-phase flow are among the many factors adding to this uncertainty With the advantages and drawbacks in mind, it is emphasized that the full extraction of the benefits of HWS in field development requires careful and detailed front end planning, as can be seen in the case history below. 


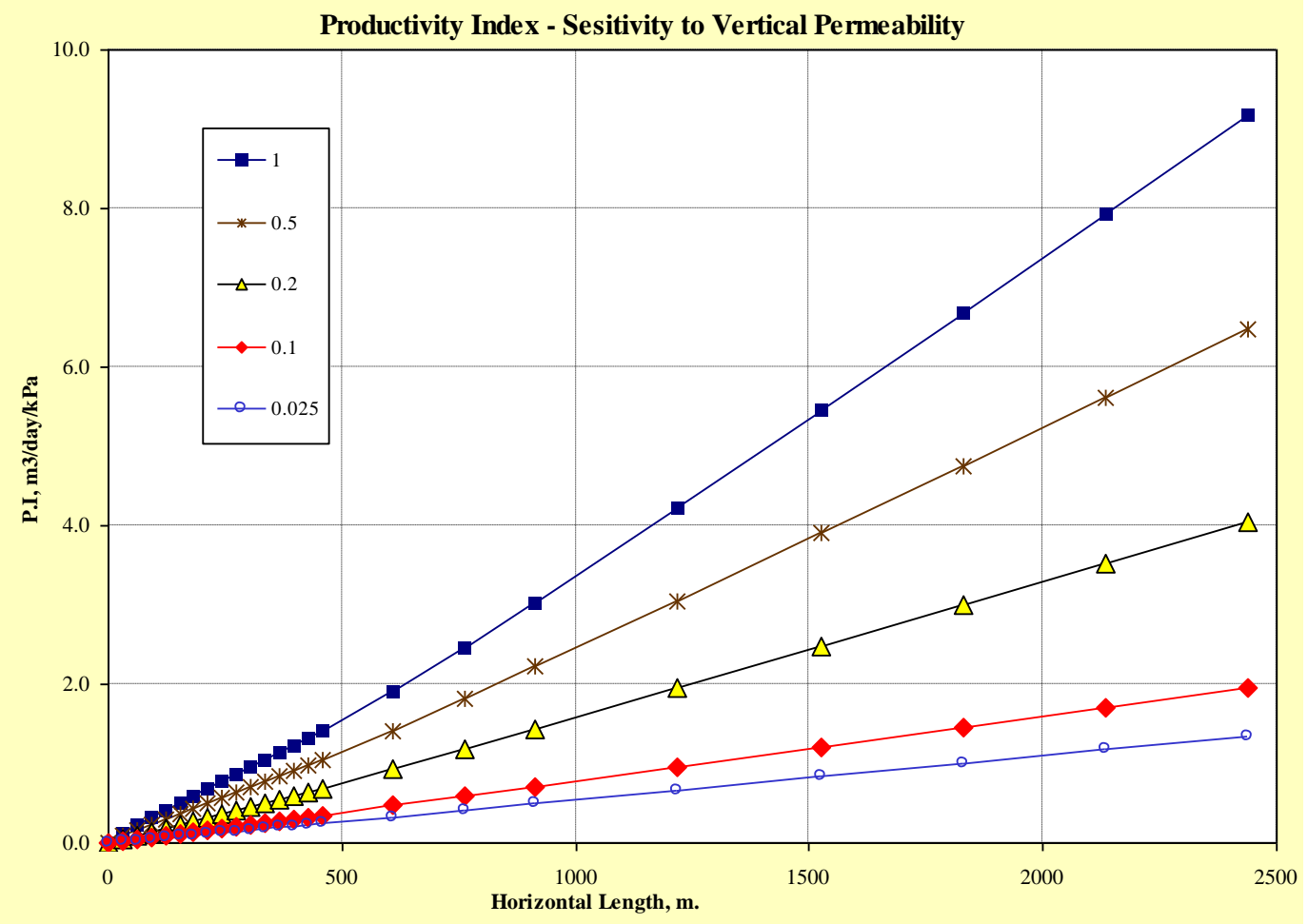

Fig.(3) Productivity of a Horizontal Well

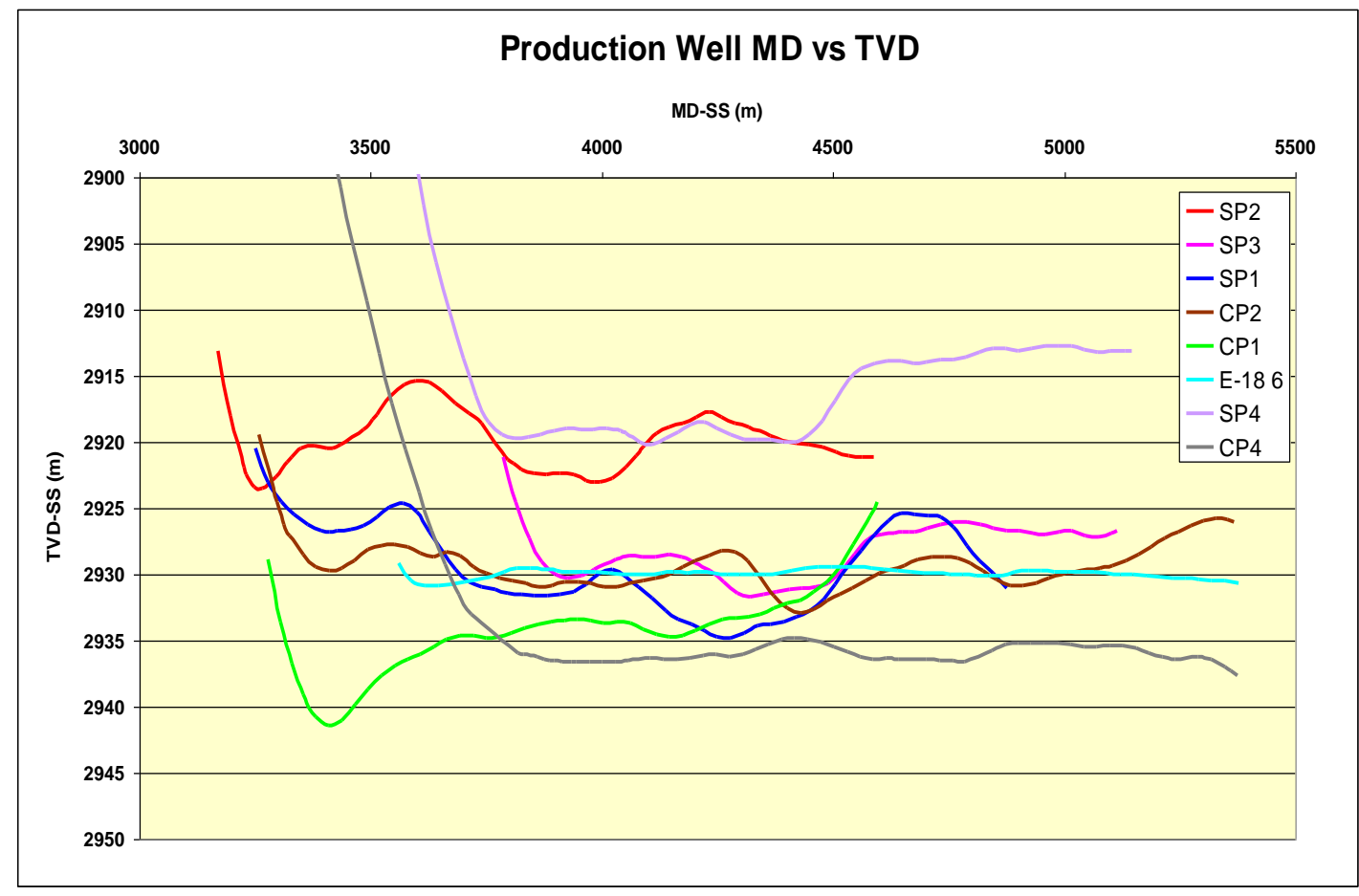

Fig.(4) Profiles of an Actual Group of Horizontal Wells 


\section{Case History 1}

\section{The discovery well in}

White Rose field, South Avalon Pool, offshore the Canadian East Coast was drilled in 1987. Three other wells were drilled in the 1990's for delineation and appraisal. The hydrocarbon accumulation comprised a medium size pool with estimated 110.0 $106 \mathrm{~m} 3$ OOIP in a $130 \mathrm{~m}$ sand package, overlaid by a significant gas cap. A limited water leg was also encountered in some wells.

Seismic data and evaluation tests have indicated a complex geological setting in the form of compartmentalization into several blocks separated by major and minor faults, with displacements of up to $240 \mathrm{~m}$ (Fig-5). In addition to missing the sand-to-sand continuity, the fault surfaces are often associated with damaged zones of reduced permeability. For all practical purposes, the faults are assumed to be sealing and hydraulic communication between the fault blocks to be missing, either partially or completely.

Due to the high cost and marginal economics, no actual development plan was considered until 1999, starting a detailed work that integrated data from 3D seismic, cores, logs, and production tests in the appraisal wells.

The Geological Model was built in an advanced geo-modeling software to represent the complex structural model, and characterize the Stratigraphic column through a reliable facies model that honors the depositional sedimentary pattern. Geostatistical tools were then utilized to populate the model with rock properties on a stochastic basis. A grid system was overlaid on the resultant geological model on a cell dimensional basis 
of $50 \mathrm{~m}$ on sides and $2 \mathrm{~m}$ thickness, resulting in about 4.5 million cells model. It was then upscaled to numerical simulation scale of $100 \mathrm{~m}$ areal and $4 \mathrm{~m}$ thick grid-cells Fig.(6) . When customized to the development area and populated with fluids, the numerical model was reduced to about $1.0 \quad 105$ active cells.

The pool consists of two main Mega Blocks in the north and south, separated by a major fault. The southern block has much less structural complexity and a fairly flat layout, with more consistent sand quality Fig.(7) . According to geological and reservoir evaluations, it holds more than $50 \%$ of the total OOIP and reserves. On the other hand, the central block is more compartmentalized and represents a group of fault blocks and subblocks of widely different sizes. It was obvious that setting a well plan that assures an efficient access to all the reserves with limited number of wells in this part will be challenging.

Early simulation runs have clearly shown that the primary recovery in the field is about $7 \%$ and that waterflood has to be implemented at production startup to achieve economic oil rates and recovery levels.

Well Planning: An intensive well planning and optimization work has followed, taking around four years to the time to spud the first well. It was carried out by a subsurface team of reservoir and simulation engineers, geologists, geophysicists, petrophysicists, and geo-modelers, with direct interaction and support from drilling, completion, production engineers, and the facility design group.

The early well optimization work in the numerical model proved that 
horizontal wells have big advantage over vertical or slanted wells for field development, as producers and injectors, and for technical and economical considerations. This is mainly attributed to the compartmentalization of the field. Practical considerations dictated that the planned wells be drilled from two drill centers (called Glory Holes), strategically positioned on the sea floor. The objectives of the well planning process were defined as follows:

- Maintaining an optimal oil rate plateau period.

- Minimizing total drilled meters.

- Optimizing the location of the Glory Holes.

- Maintaining an optimum wellspacing and a "safe" distance to fault surfaces.

- Optimizing the vertical position of the horizontal producers and injectors.
- Water injection to achieve a voidage replacement of $1: 1$ on all major blocks level.

- Optimizing Injection wells' orientation to avoid early water breakthrough.

- Improving sweep efficiency on fault block basis.

- Investigating the number and location of potential infill wells.

The well planning process passed through many overlapping phases, following the progress of the team understanding of the reservoir and geologic setting. In each phase, the optimized set of wells was subjected to a series of tests, whereas the numerical simulator was repeatedly run to verify the sensitivity of the model to a number of anticipated factors and risks, such as the sealing strength of the faults, potential of horizontal barriers in the reservoir, and wellbore dynamic effects. 


\section{Phase I- Preliminary Phase II- Simpler Wells:}

\section{Horizontals:}

The first pass of the well plan Fig.(8) proposed a set of curved long horizontals that lay basically parallel to the fault trajectories, comprising 8 producers and 5 injectors, on general basis of 2:1 in the bigger blocks and 1:1 in the smaller blocks, with laterals of up to $3200 \mathrm{~m}$ in length. This set of wells was forecasted to achieve a recovery of $40 \%$ of the OOIP over 15 years. Vertically, the producers were optimized to be placed in the upper half of the oil column, slightly closer to the GOC, while the injectors were to lay at or

below the OWC within $50 \mathrm{~m}$. The forecasted oil rate plateau was 16.0 $103 \mathrm{~m} 3 / \mathrm{d}$ with maximum injection requirement of $40.0 \quad 103 \mathrm{~m} 3 / \mathrm{d}$. These two limits have set the outlines of design for the offshore facilities. The forecasted per well oil rate was up to $4.0103 \mathrm{~m} 3 / \mathrm{d}$.
Close analysis and investigation indicated many problems with the previous well plan. In addition to the drilling technology challenge*, it was thought to be useful to keep the wells at a safe distance from the fault surfaces. Observations of cores and analog cases have shown that the damaged zone near the faults could seriously impact the well productivity. Accordingly, a simpler well set was re-worked, keeping the same well count and general positions, but with straightened laterals that lay about $200 \mathrm{~m}$ from the faults. The new wells were shorter, but with marginal impact on productivity.

(*) Reference to the period around 2001

\section{Phase III- Revising Injection Wells:}

The depletion plan requires that cold sea water to be injected into the reservoir, where the formation 
temperature is $105 \mathrm{C}$. Under these circumstances, and even below fracture pressure, the risk of creating spontaneous fractures in the injection wells due to the combined thermal-hydraulic effects is very high. Analog cases in the industry are well known(2). In a horizontal well, the part that most likely to be impacted is the heel side where the injection pressure is highest. Planning for long injectors that should feed into more than one block, this situation could seriously risk the recovery efficiency on the toe side of the

well. It also holds the threat of early water breakthrough in the producer.

To account for these risks, few modifications were introduced:

- The original 'all horizontal' well plan was modified to have vertical injectors in the southern block of the field, replacing each horizontal injector by two verticals.

- The horizontal injectors in the northern part are to be limited to two blocks, and to be equipped with 'smart' downhole valves to control the flow path and divert injected water to both parts of the well.

- The orientation of horizontal injectors is to take into account the distribution of formation mechanical stresses, whenever possible. The ideal orientation is parallel to the principal stress axis, such that any induced fracs would be along the wellbore, minimizing the risk of communicating to the producers. To the best available data, this direction is also parallel to the main faults. 
- The events of induced fracs and smart completions were built into the simulation model as additional features in the injectors.

The change to vertical injectors represented a significant shift in the depletion strategy of the reservoir; as the original bottom water drive with horizontal injectors in the southern block is modified now into a more like line drive. The model shows some improvement in the vertical sweep efficiency if injection in the oil zone is activated, helping to recover oil from the 'disk' area laying above the producing wells (Fig-9), but on the account of increasing the well count. At this stage, the plan became to drill 7 horizontal producers and 8 injectors (2 horizontals and 6 verticals), as shown in Fig-10.
Phase IV- Drilling Start-up Wells:

As the startup of drilling campaign approached, the focus turned to optimize the wells that come early into the drilling schedule, especially the first horizontal producer in the Southern Block. Due to the North Atlantic weather restrictions, the drilling and well completion

operations have to proceed on seasonal basis. An optimized schedule was put to drill half the full number of wells for the first oil. In the simulation model, the drilling schedule was introduced together with updated operational well constraints like minimum BHFP, maximum BHIP, and the limits on oil, gas, and water quantities to be handled, as supplied by the finalized engineering design of the project.

In close coordination with drilling engineers and geologists, a 
detailed process to optimize the actual placement of the first horizontal was initiated. The performance of the well is directly related to its position, both vertically in the oil zone (TVD) and laterally (Azimuth). It will characterize the gas coning from gas cap and water breakthrough from offset injectors. While the model can select an ideal positioning, the real location of the well in the ground is governed by the directional measurement accuracy, which in turn depends on the choice of the type and frequency of surveys.

Keeping a cost effective survey program, the drilling engineers defined a 'Drilling Box' for the error range of directional surveys. This box can be imagined to fall inside a bigger 'Geological Box' which defines the prognosis error in the target depth. The simulator was used to test the sensitivity of the vertical and lateral placement of the well within the error margin, defining an acceptable range to ensure that the impact on the well's future performance is minimal. The optimum vertical position was defined for the first producer to be at $46 \mathrm{~m}$ in GOC stand off, with a $\pm 5 \mathrm{~m}$ vertical error window Fig.(11) . It was also found that the lateral azimuth position is less critical within a window of $\pm 25 \mathrm{~m}$.

\section{Phase V- Final Operating Well}

\section{Set:}

As per the development plan, oil production was started in November 2005 upon drilling and completing 3 producers and 6 injectors, while the remaining wells were progressively drilled over a period of 4 years. A huge stream of new data was acquired to benefit the planning of later wells in drilling schedule(3), particularly in the northern part of the field 
with more faulting. Dynamic well performance data from production and injection, with pressures from the permanent downhole recorders, in addition to new geological and petrophysical data, were consistently used to calibrate the simulation model. The integration of multi-disciplinary data helped to better characterize the heterogeneity in the northern block, which was shown to comprise double the initial number of sub-blocks. The excessive faulting in this part dictated adding an infill vertical injector, while the better performance of the southern part encouraged adding an infill horizontal producer. The final development well plan of the pool consisted of 8 producers, 3 horizontal injectors, and 7 vertical/deviated injectors, as shown in Fig-12.
The actual well performance showed oil rates per well that exceeded $4.8103 \mathrm{~m} 3 / \mathrm{d}$ in the plateau period. As a result, the offshore facilities were revamped to accommodate higher total field production, reaching a peak rate of 21.5 103m3/d in 2007 Fig.(13) . Diligent planning has succeeded in achieving a remarkable well and reservoir performance, recovering more than $50 \%$ of reserves in the first 5 years of production life. 


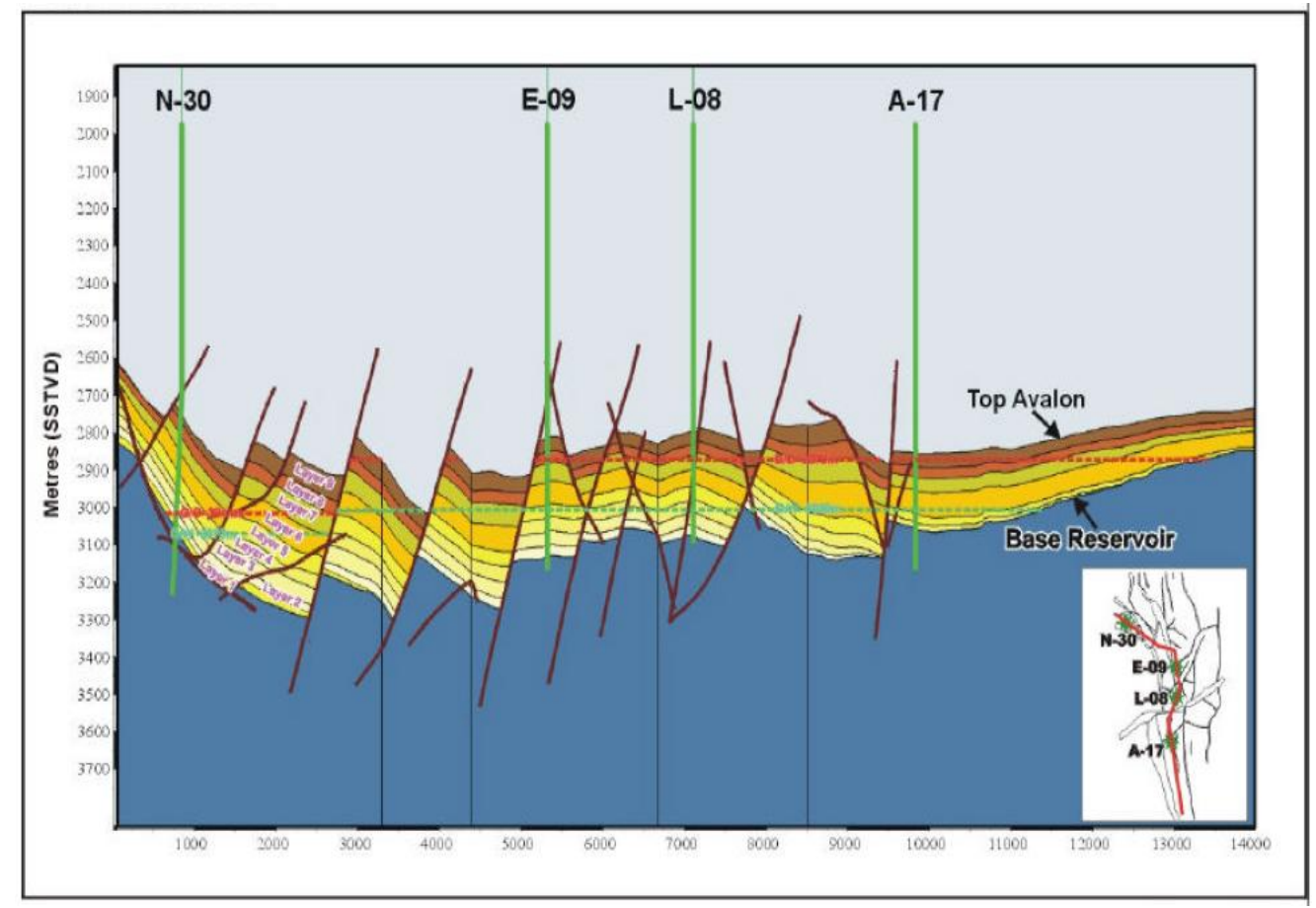

Fig.(5) White Rose Field, Structural Cross-Section

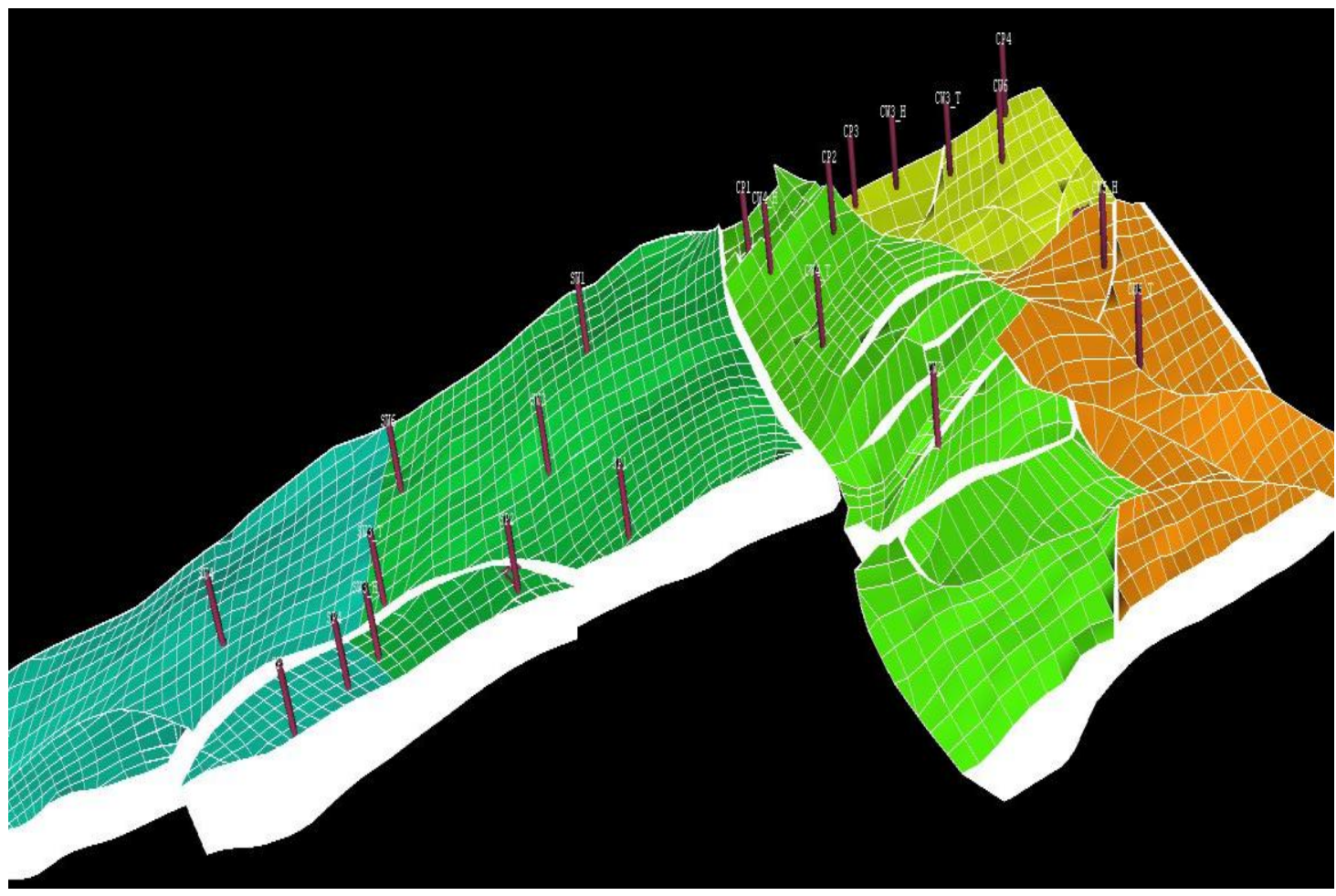

Fig.(6) White Rose Field, Numerical Simulation Model

$1^{\text {st }}$ Iraq Oil \& Gas Conference ( $\left.1^{\mathrm{ST}} \mathrm{IOGC}\right)$ 


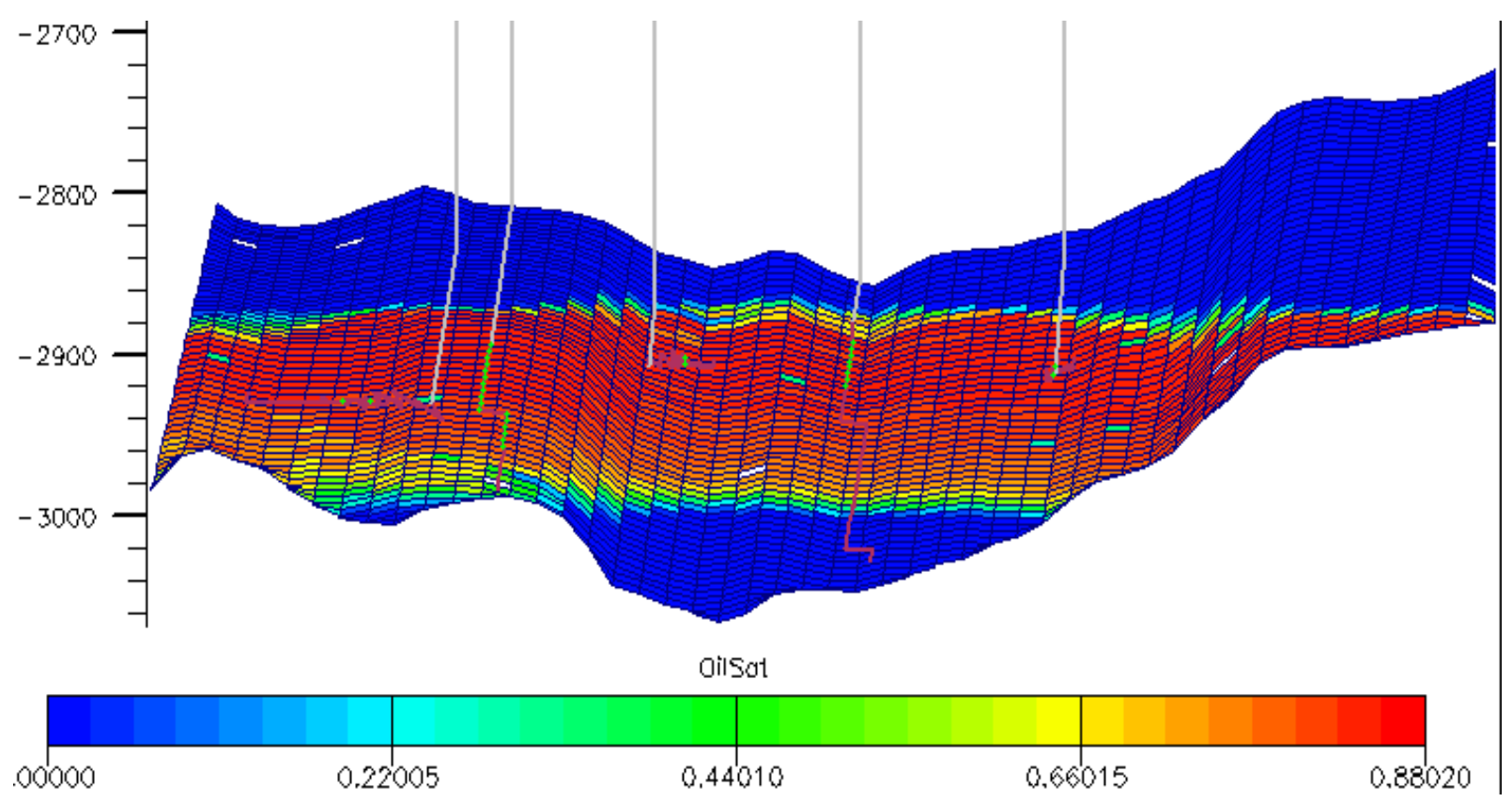

Fig.(7) White Rose Model, Cross Section in the Southern Block, Initial Conditions

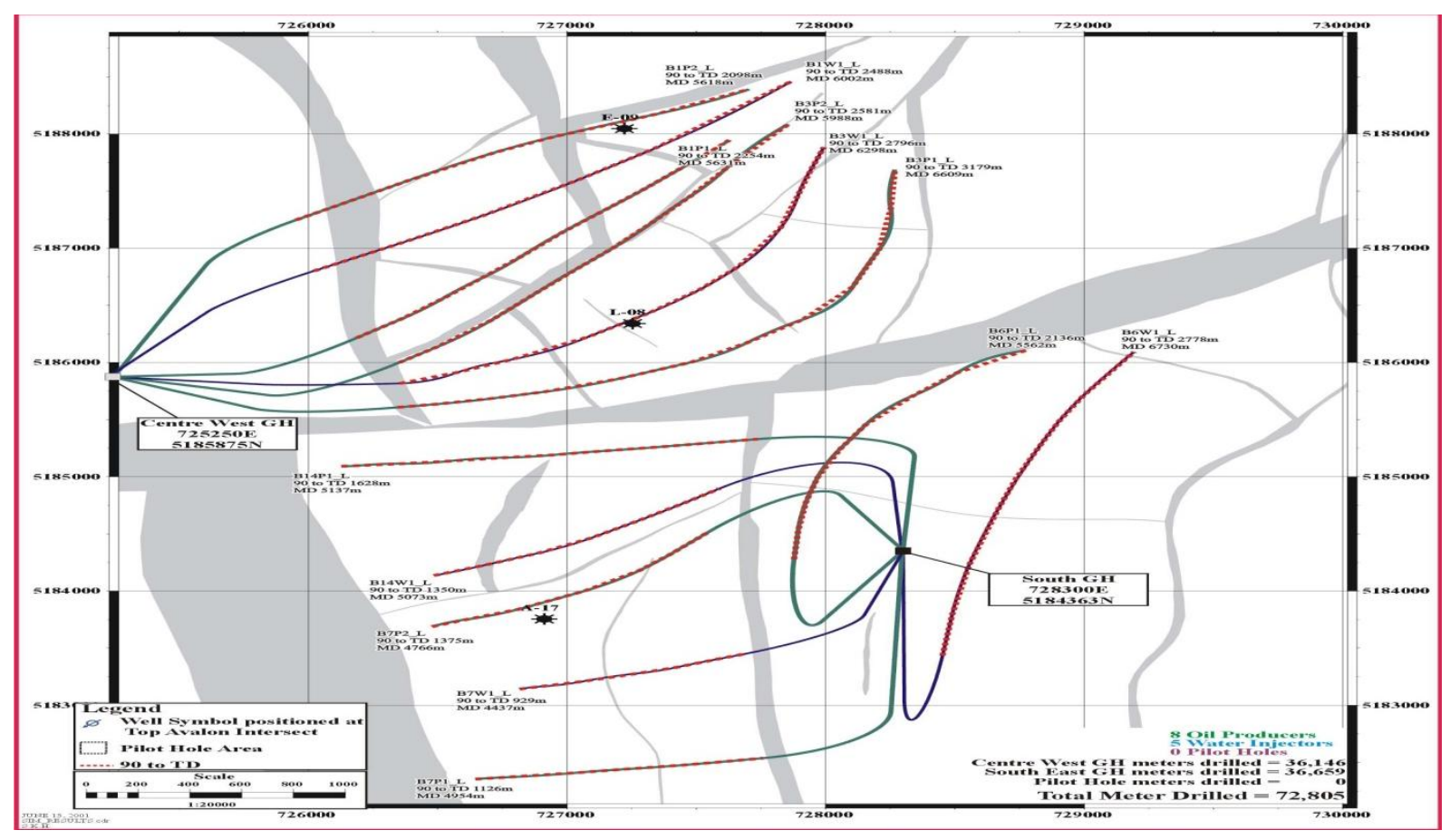

Fig.(8) White Rose Field, Preliminary Well Plan

$1^{\text {st }}$ Iraq Oil \& Gas Conference (1 ${ }^{\text {ST }}$ IOGC) 


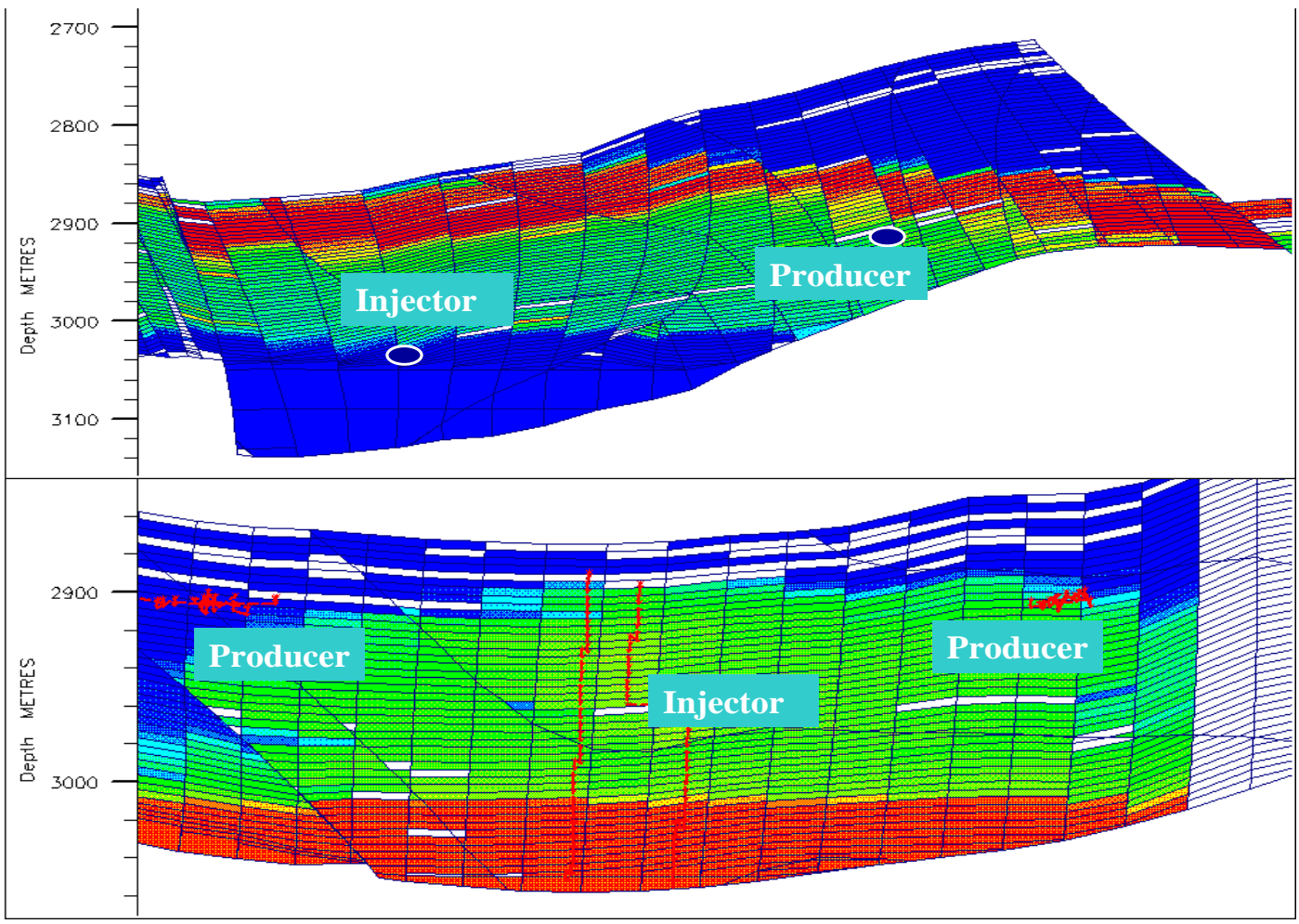

Fig.(9) White Rose Field, Sweep Pattern with Horizontal and Vertical Injectors

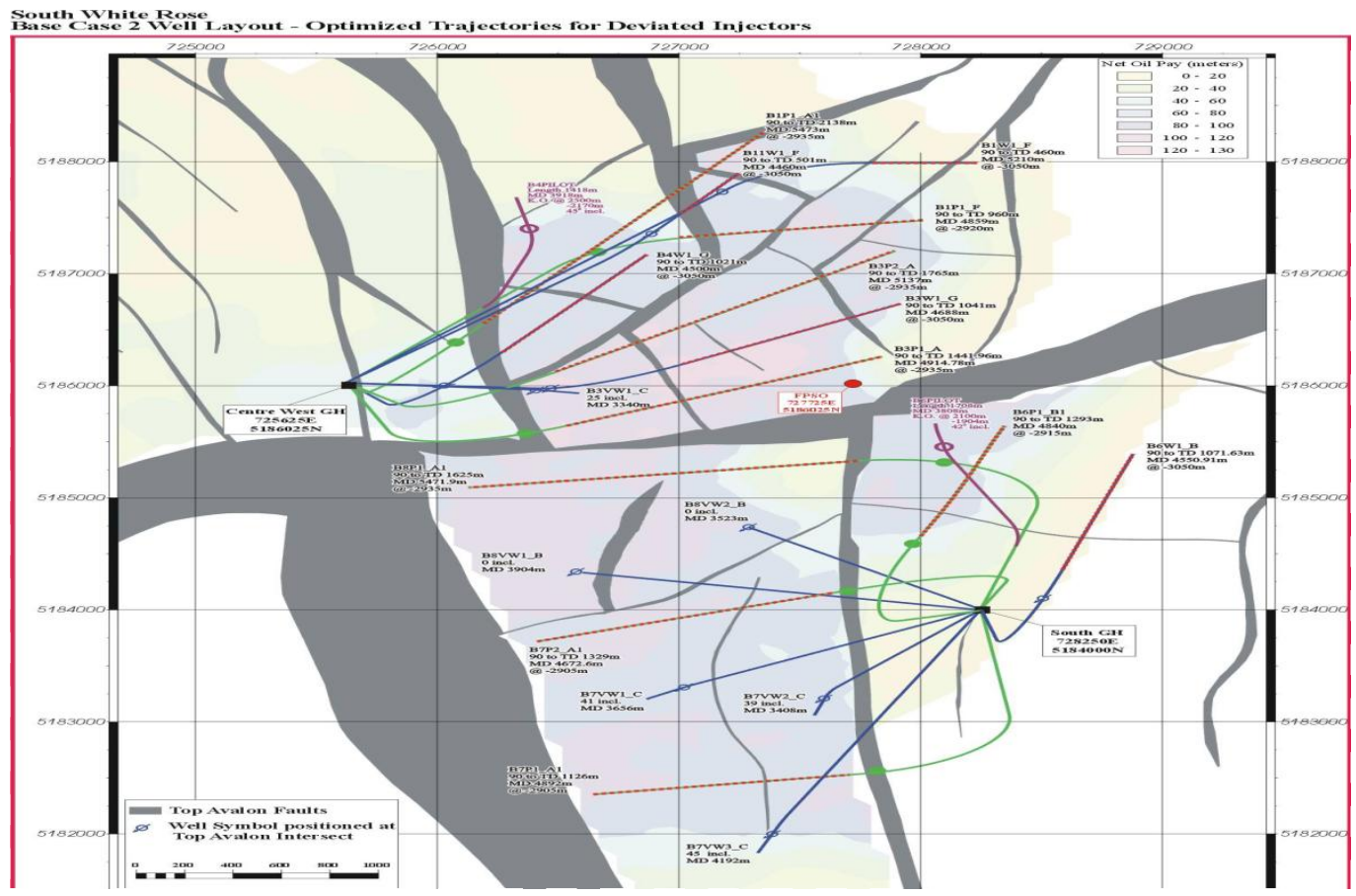

Fig.(10) White Rose Field, Revised Injection Wells

$1^{\text {st }}$ Iraq Oil \& Gas Conference ( ${ }^{\text {ST }}$ IOGC $)$ 


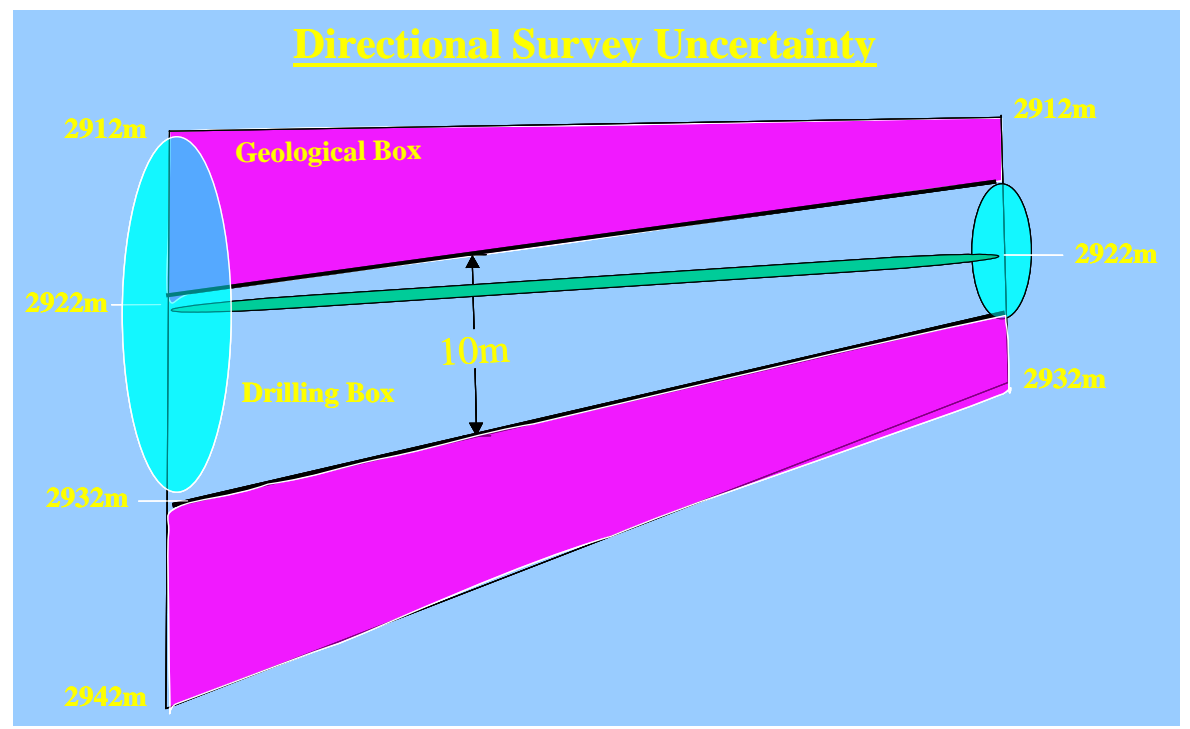

Fig.(11) White Rose Field, Uncertainty in Vertical Positioning of HWS

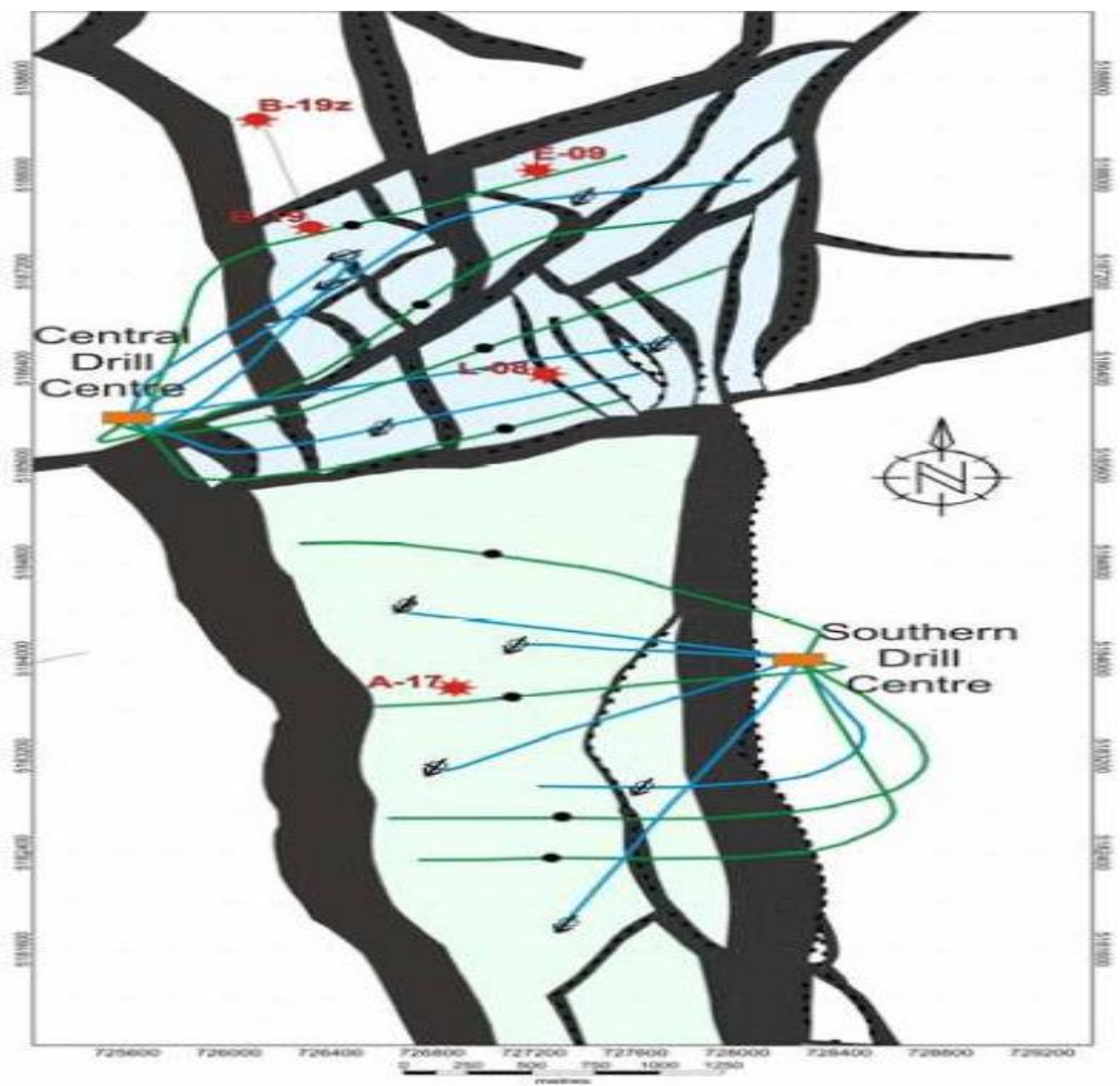

Fig.(12) White Rose Field, Final Operational Well Plan (Ref.3) 


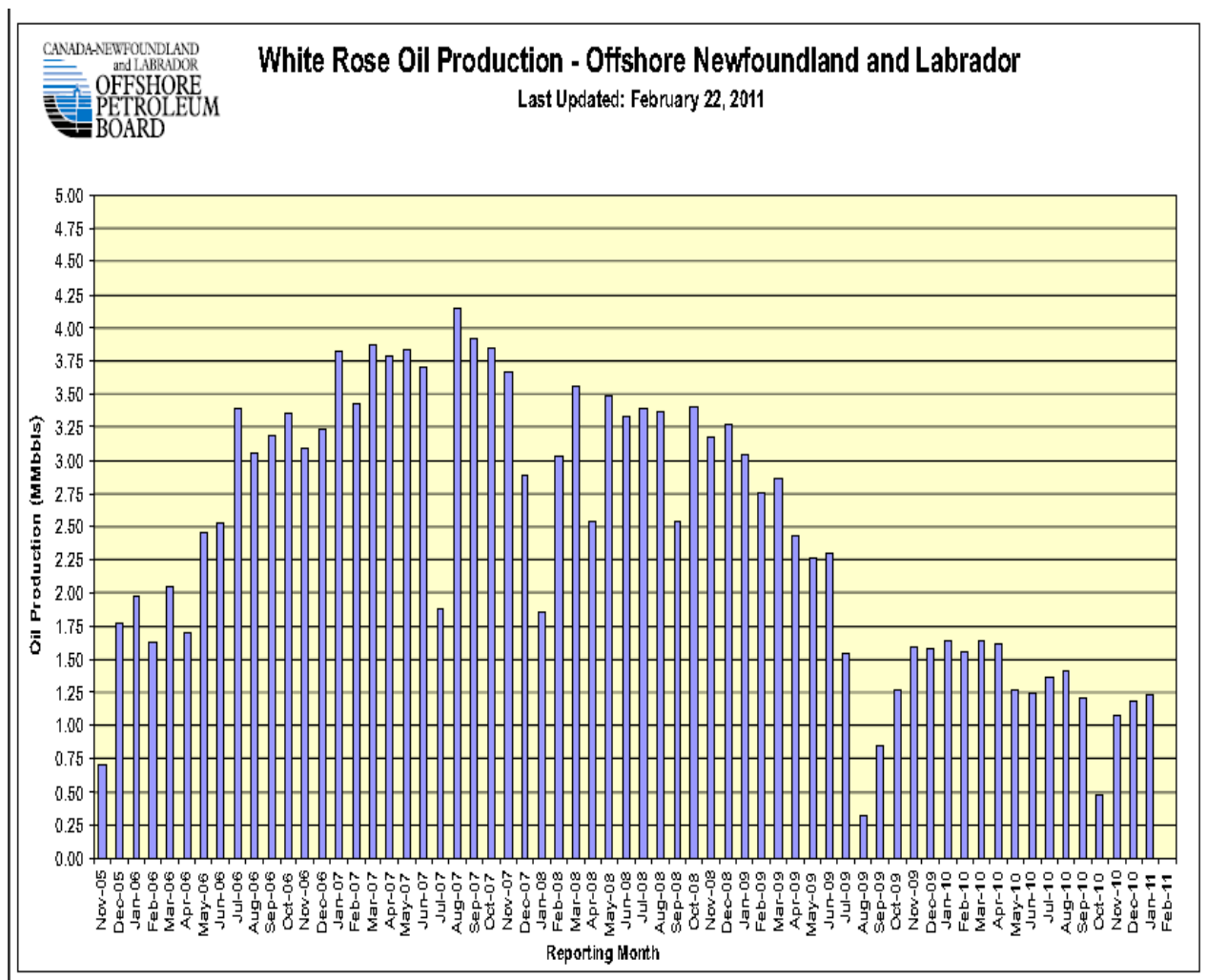

Fig.(13) White Rose Field, Oil Production Performance (Ref.4)

\section{Horizontal Wells In Numerical}

\section{Simulation Models}

Basically, numerical

simulators handle HWS in the same way as verticals. The main distinction which might introduce potential calculation errors is related to the longer wellbore. Two pertinent aspects are discussed here.

\section{Discretization:}

The longer lateral length results in the number of well's connecting cells to be potentially 1-2 orders of magnitude more than a corresponding vertical well, 
leading to a higher discretization error. The gridcell size and geometry both have an impact, together with the well's orientation. Even if the Grid geometry is highly orthogonal, a diagonal wellbore will yield a zigzag-shaped trajectory. It is to be recalled that in the simulator, the 'Well' is basically a group of gridcells that has a Sink or Source terms in the solution matrix, and have (like all other cells) the mathematical solution at their centers. The well is actually connecting the cells' centers, and the deformation of the well trajectory could have a significant impact on its modeled performance. As an example, some of the wells of Fig.(12) are shown in Fig.(14) when placed in the Grid of the reservoir model of Case History 1.

Another example is worked here using the orthogonal Box Model, comparing two cases whereas the only difference is the gridcell size. The impact of the cell size on productivity is shown in Fig.(15), showing some $2 \%$ increase for the coarser grid, while the change in pressure field is shown in Fig.(16). It should be noted that showing the well here as a straight line is only a graphical demonstration, and the 'numerical well' actually comprises all the cells intersected by trajectory path, as described earlier. In some sophisticated simulators, the length contribution to the wellbore of each individual cell is prorated, to reflect the actual intersected length.

\section{Wellbore dynamics:}

In real life HWS, the pressure losses are usually large as compared to VWS, due to the longer wellbore. The importance of this effect is aggravated by the trend of the majority of 
simulations to be run at when simulating HWS. Some bottomhole conditions, with commercial simulators have an correction to a certain datum. optional aide to make up for While the practice could be friction losses, which may be used acceptable for VWS, neglecting at least in conducting sensitivity the frictional effects will introduce Runs.

a bigger error in performance

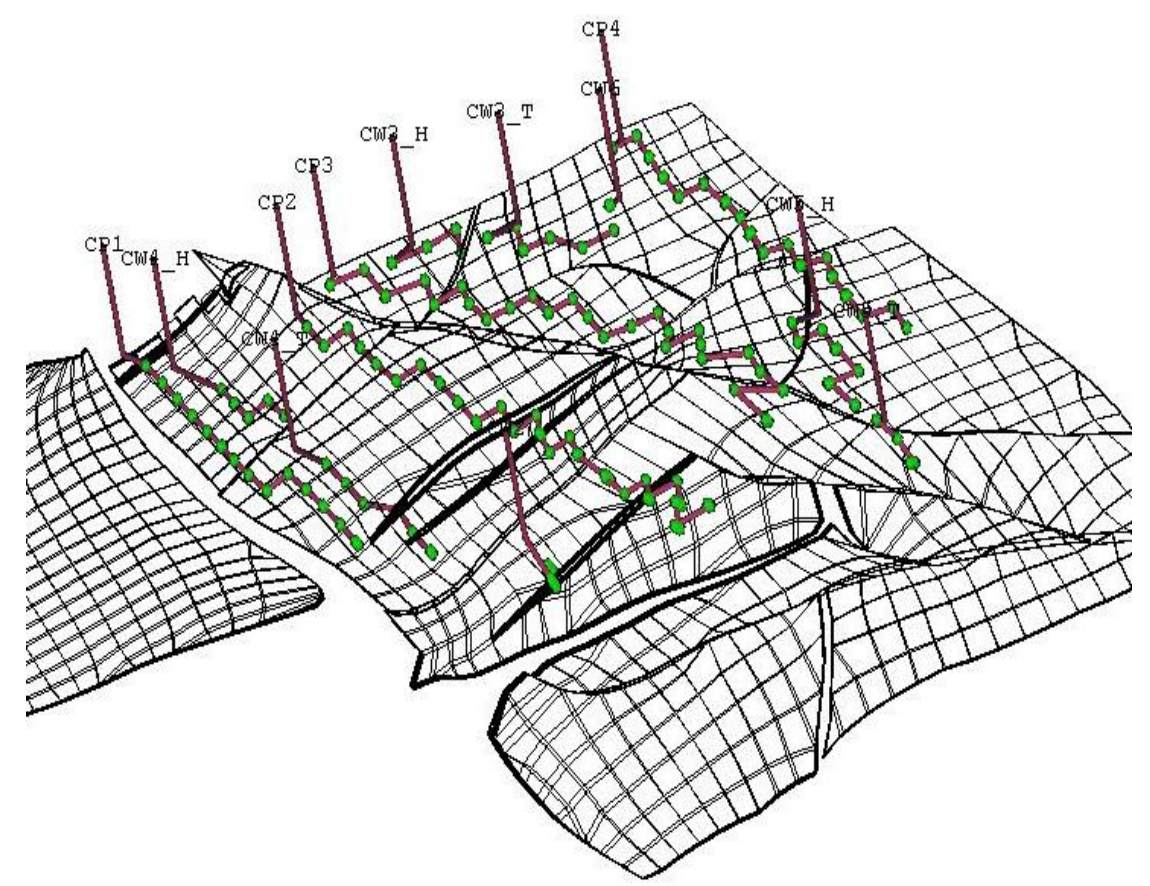

Fig.(14) Horizontal Wells Representation in a Numerical Reservoir Model 


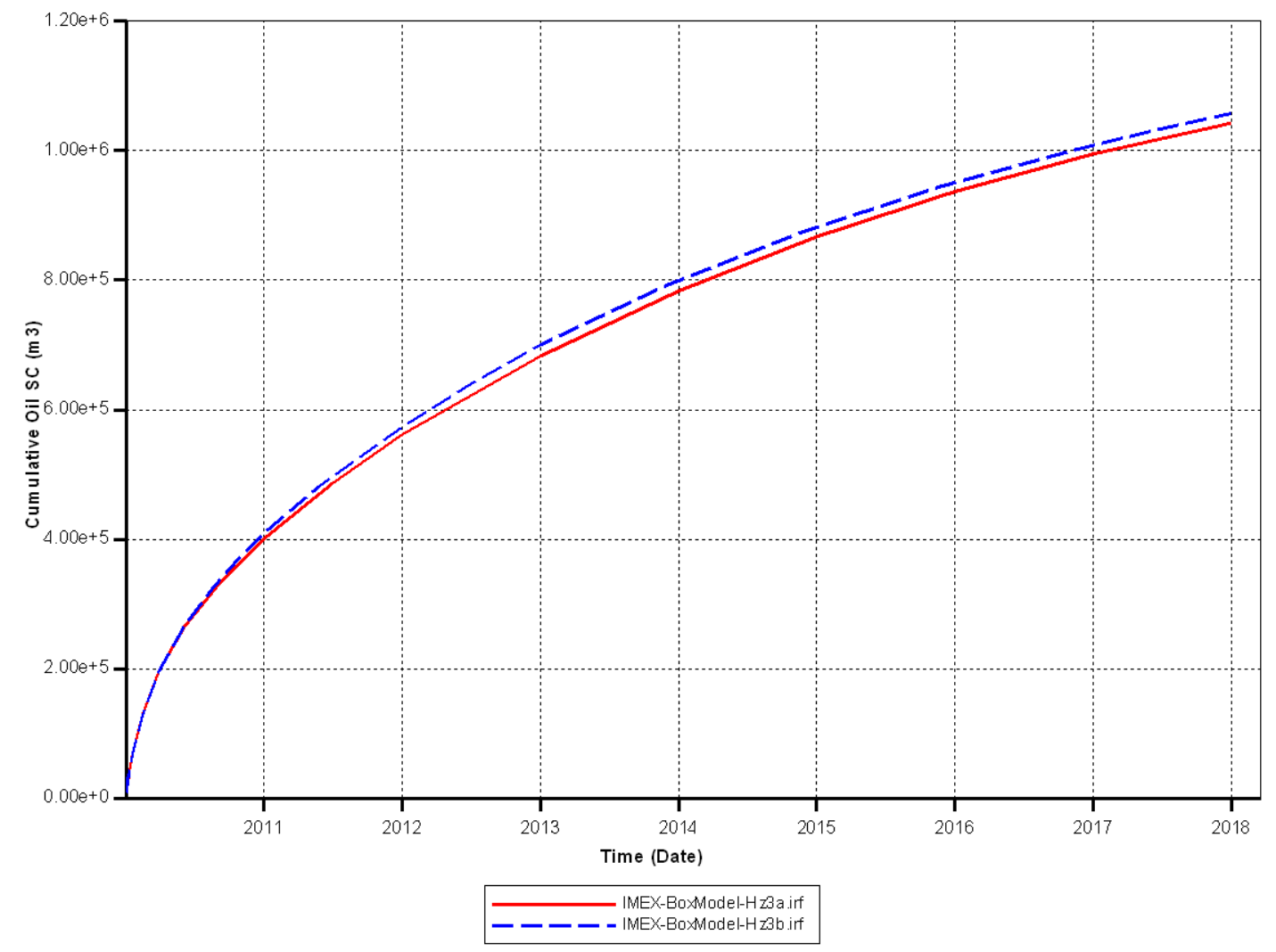

Fig.(15) Impact of Simulator Gridcell Size on Productivity of HWS 


\section{Journal Of Petoleum Research \& Studies}
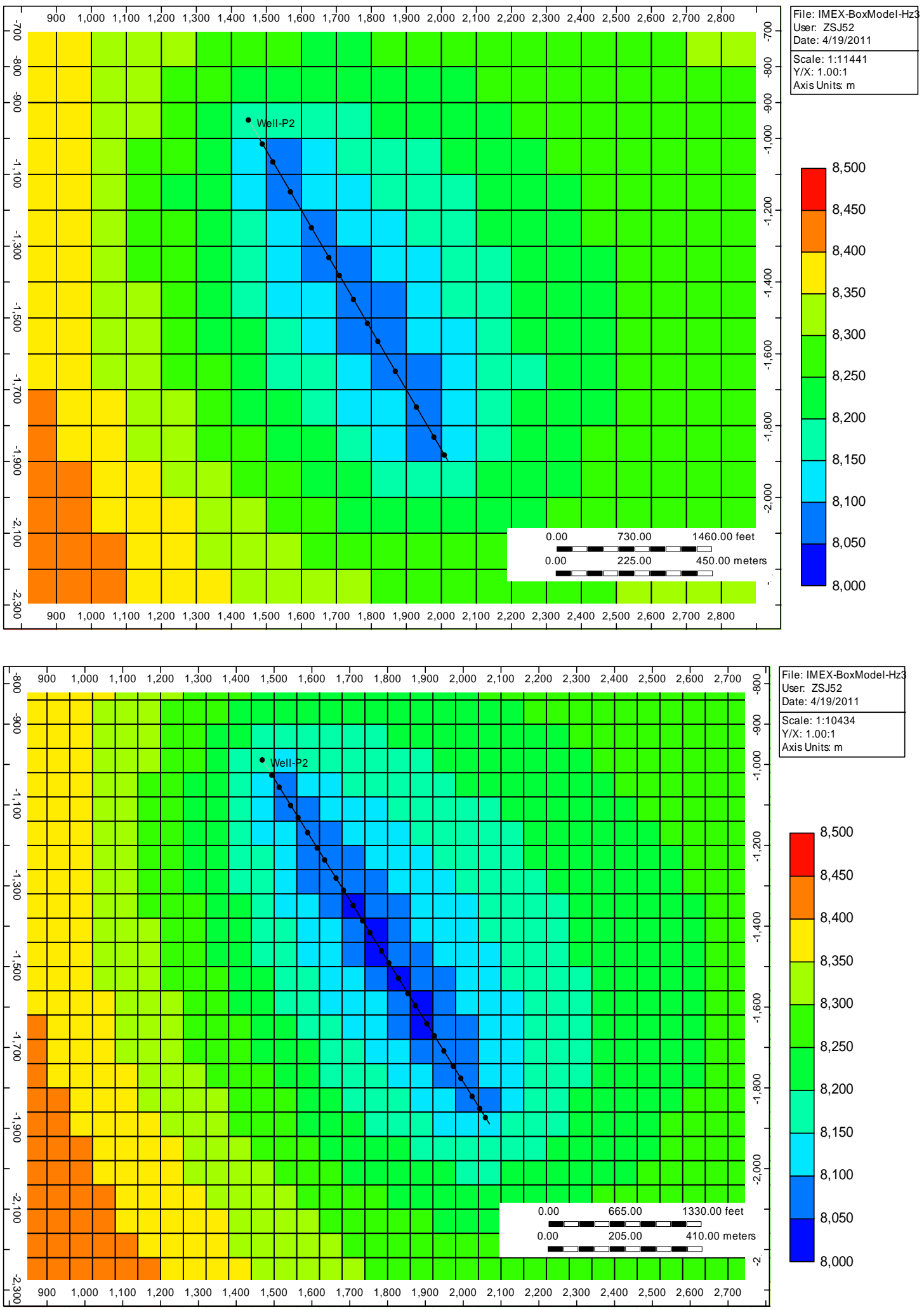

Fig.(16) Impact of Simulator Gridcell Size on Pressure Gradient around HWS

$1^{\text {st }}$ Iraq Oil \& Gas Conference ( $1^{\text {ST }}$ IOGC) 
Horizontal Wells in Pressure Transient Analysis (PTA)

Flow Regimes in Pressure

\section{Transients}

Since the early 1980's, the identification of flow regimes has been established as the basis for welltest analysis, with the log-log pressure derivative plot as the main diagnostic tool ${ }^{(5)}$. For the simpler case of a fully penetrating VW in a homogeneous reservoir, the Infinite Acting Radial Flow regime will show as a flat (Constant derivative) line, following the initial (non reservoir) regime dominated by wellbore storage effects Fig.(17) . In this scheme, flow takes place solely in a horizontal $x-y$ plane, with no vertical flow component.

For the case of horizontal well, a radial flow regime over the whole well's drainage area will still show as a flat derivative line, but many reservoir flow regimes could occur prior to this final radial flow, depending on the fluid properties, wellbore and reservoir geometry, and the distribution of transmissibility in 3-D space. Fig.(18) shows the various regimes in an idealized case, representing a HW of 2,500m lateral length, centered within a $20 \mathrm{~m}$ medium gravity oil zone with $100 \mathrm{mD}$ horizontal permeability and $\mathrm{K}_{\mathrm{v}} / \mathrm{K}_{\mathrm{h}}$ of 0.1, and with No-Flow Barriers on top and bottom. These are the same basic conditions used to generate the curves for the vertical well of Fig.(17).

The first regime to observe for HW test data is often the wellbore storage (WBS), as wells are usually shut-in at the wellhead, not the sandface. It will show as a unit slope line on both curves ( $p$ and p') in a log-log plot. It is 
interesting to note that while the wellbore volume for a HW could be much larger than a VW with the same fluid properties, the effect is offset by the higher value of $\mathrm{L}_{h}$, and the time for end of WBS is of the same order of magnitude ${ }^{(6)}$. This phase is purely a wellbore effect and can give no information on the reservoir flow.

The first reservoir pressure response is the initial radial * flow regime that occurs in the vertical plane perpendicular to the well's axis, with a flat derivative line. The second phase to follow is a linear flow regime in the horizontal plane, with a line of half slope on the pressure derivative. It occurs when the flow is dominantly parallel to the barrier surfaces above and below the well's axis. With increased flow contribution from the two ends of the wellbore, a transition flow

(*) More likely elliptical in shape, as normally $\mathrm{Kv}<<\mathrm{Kh}$ regime may show in the form of nearly $1 / 3$ slope line, ending when the final radial flow regime prevails, with a reservoir-wide contribution.

\section{Analogy to Fractured Wells:}

It has been recognized that the behavior of a HW bears a good similarity to that of a VW with a very high conductivity induced fracture. The extent of analogy increases under conditions of small pay thickness and higher vertical conductivity $^{(1)}$. In terms of flow regimes, the linear and final radial regimes are common between the two well models. If the HW itself is fractured, its behavior will come closer to that of a fractured vertical well.

\section{Analysis of Pressure Transient}

Data:

In mathematical formulation, and assuming a vertically centralized HW case with no completion 
damage, the unknown variables to solve for are at least three; $K_{h}, K_{v}$, and $\mathrm{L}_{\mathrm{h}}$. This is to compare with one unknown $\left(\mathrm{K}_{\mathrm{h}}\right)$ in a VW case. For analysis purposes, the development of the final radial flow is required to nail down the sequence of calculations for the other unknowns and avoid assumptions.

From the initial radial flow, the flow capacity is calculated in a manner similar to that of Horner's straight line in vertical wells ${ }^{(6,7)}$ :

$$
\mathrm{K}_{\mathrm{r}} \cdot \mathrm{L}_{\mathrm{h}}=2149 \mathrm{q} \cdot \mu \cdot \mathrm{B} / \mathrm{m}_{1}
$$

with $\quad K_{r}=\sqrt{ }\left(K_{v} \cdot K_{h}\right)$ is the average permeability in the vertical plane. The lateral length $\left(\mathrm{L}_{\mathrm{h}}\right)$ has replaced the pay thickness in the flow capacity term, as the HW is taken to resemble a VW rotated at $90^{\circ}$. The slope $m_{1}$ is for the semi-log line corresponding to the first radial flow regime.
From the linear flow regime, the effective lateral length can be determined as follows:

$\left(\sqrt{ } K_{h}\right) \cdot L_{h} \cdot H=12.5$ q.B. $\sqrt{ }\left(\mu / \Phi \cdot C_{t}\right) / m_{2}$ The slope $m_{2}$ here is for the linear flow corresponding line on a plot of (pressure vs. $\sqrt{ } \mathrm{t})$.

$\mathrm{K}_{\mathrm{h}}$, the horizontal formation permeability, can only be obtained explicitly from the final (pseudo) radial flow, using slope $m_{3}$ of the semi-log plot line corresponding to the final radial flow regime, in a fashion similar to the first radial regime:

$$
\mathrm{K}_{\mathrm{h}} \cdot \mathrm{H}=2149 \mathrm{q} \cdot \mu \cdot \mathrm{B} / \mathrm{m}_{3}
$$

These equations show that only when all the regimes are identified, the basic three unknowns $\left(\mathrm{K}_{\mathrm{h}}, \mathrm{K}_{\mathrm{v}}\right.$, and $\mathrm{L}_{\mathrm{h}}$ ) can be resolved. In practice, it may be difficult to identify some or any of these regimes from field data. 
Depending on the geometrical and petrophysical features, the test pressure signal may look just like that of a VW. Fig.(24), (of Case History 2) is an example of a field data set with fairly good flow regime definition, while Fig.(19) shows a $700 \mathrm{~m}$ lateral that has a pressure response mostly similar to a VW. In tight reservoirs, the final radial flow regime may not be reached unless the shut-in time for buildup is impractically long. Also, noise in data can obscure some of the useful features in the response signal, while the first radial regime is likely to be masked by wellbore storage. Eccentric well position with respect to the flow barriers above and below, existence of thin shale

streaks, and formation directional permeability are other reasons that may cause distortion to the pressure response. For practical purposes, commercial software use several techniques, such as Type Curve matching and regression, to perform the transient analyses.

\section{Skin Factor Components:}

Unless the formation damage resulting from drilling and completion is high, horizontal wells are generally expected to show some negative Skin factors, typically ranging -2 to -4 . Equations to solve for the different skin components can be found in welltest literature ${ }^{(6,7)}$, after solving for the permeabilities and lateral length from the equations shown above.

Skin factor for a horizontal well comprises two major components:

- Mechanical skin factor, representing the completion damage (or stimulation) near the sandface. It also could reflect the lack of contribution of some parts of the horizontal length, being either unproductive or un-perforated. 
This effect can best be evaluated during the first radial flow regime.

- Geometrical Skin Factor, representing the distortion of flow streamlines when approaching the horizontal wellbore. This effect will only show in the linear flow and final radial flow. Its major component is the "Convergence Skin" resulting from the deviation of flow in the plane vertical to the well's axis (Fig-18). Convergence effect is a function of the contrast of vertical and horizontal permeability, decreasing for smaller contrast and longer wellbores.

\section{Horizontal Wells In Rate} Transient Analysis (RTA)

Rate Transient Analysis is a relatively new technique that was developed over the past three decades. It became commercially available only in the last ten years, and was promptly recognized by the industry as a powerful engineering tool. It involves the analysis of well performance data (rates and pressures) over an extended period of time to come out with formation and wellbore characteristics similar to the PTA, in addition to the estimation of reserves. Most of the successful practical application so far has been in gas wells, although in theory it works as good for oil wells $^{(8)}$.

Out of the many techniques available under RTA, only few deal specifically with horizontal wells. As most of the published Type Curves (Blasingame, Fetkovitch, Agarwal-Gardner, Normalized Pressure Integral, and others) focus on the pseudosteady-state (PSS) period of the historical well data, the well 
geometry becomes less

significant. The normal "Radial

Flow" type-curves for vertical

wells can be used for analysis, recalling that horizontal wells typically take less time to reach pseudo-steady-state than verticals in the same reservoir.

The Blasingame approach ${ }^{(9)}$ is one of the most popular, and has an option for HWS modeling under a range of geometrical settings, representing the lateral length relative to the drainage area. To use this approach, however, an initial assumption should be made for the effective lateral length. Most of the other type-curve sets accommodate a "Fractured Well" option which is fairly adaptable, recalling the similarity in behavior of horizontals and fractured verticals. 

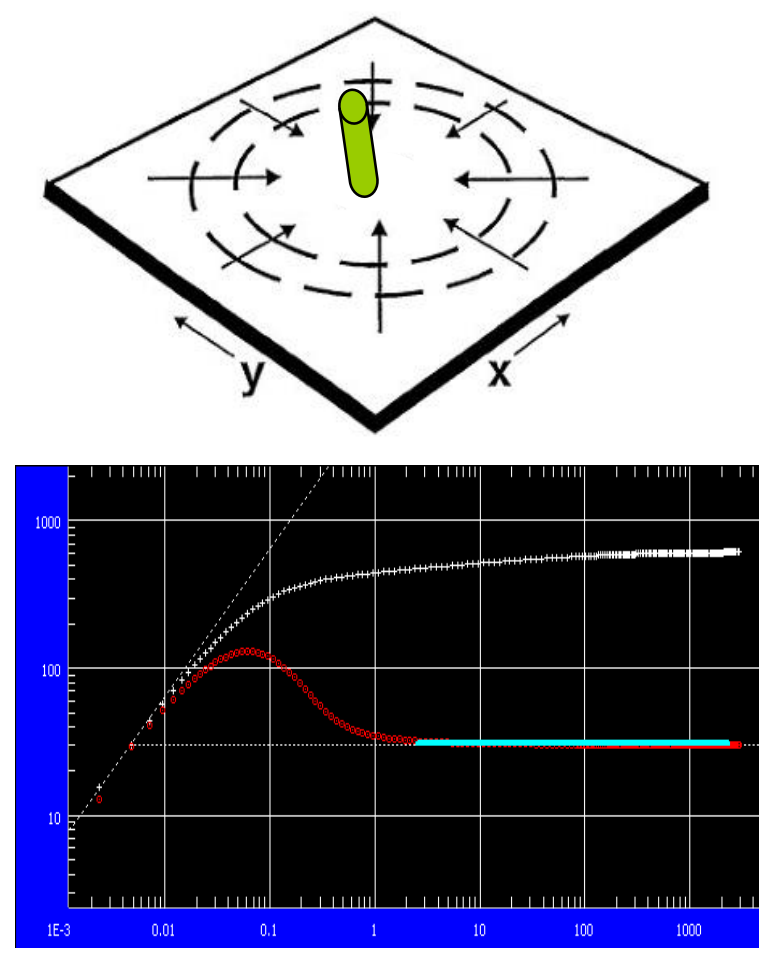

Fig.(17) Typical Flow Regimes in a Vertical Well Pressure Transient

Two examples of RTA are shown here for HWS with 700$800 \mathrm{~m}$ lateral drilled lengths in the same zone of a tight gas field in western Canada. The first well is analyzed using production data of only three months after startup. Blasingame Type-Curve match Fig.(20a) shows that the well might not be fully dominated by the drainage boundaries, and the application of PSS analysis could yield erroneous results. A match to a Transient Type-Curve set in Fig.(20b) resulted in reservoir and wellbore parameters $(\mathrm{k}, \mathrm{S})$ that are in good agreement with those of a PTA conducted earlier on the well. The fracture half length here $\left(\mathrm{X}_{\mathrm{f}}=165 \mathrm{~m}\right)$ is used as an estimate for the lateral length, which is equivalent to $2 \mathrm{X}_{\mathrm{f}}$. The well was drilled with $700 \mathrm{~m}$ lateral; therefore about half of the length is ineffective. 


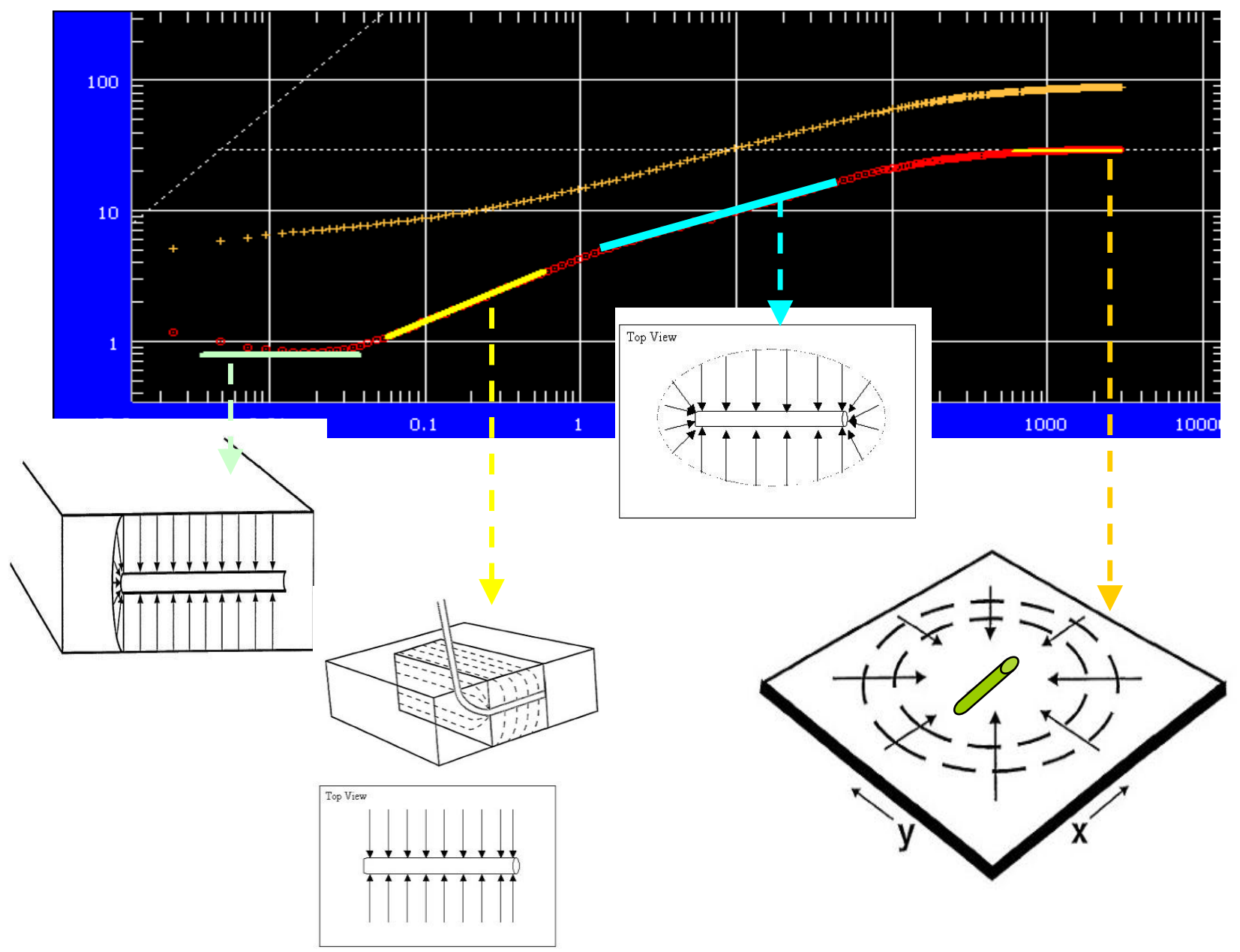

Fig.(18) Typical Flow Regimes in a Horizontal Well Pressure Transient

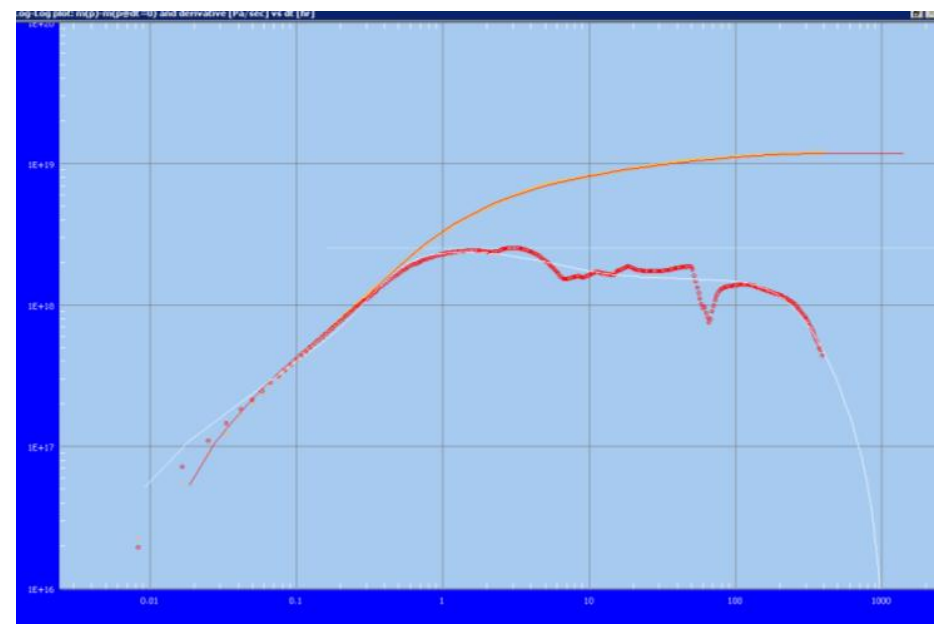

Fig.(19) Field Example of a Horizontal Well Pressure Transient Test with No Clear Definition of Regimes 
In the second well, the Blasingame type-curves were applied to one year of performance data, showing the well to have clearly reached boundary effects where PSS is dominating a good portion of the later data Fig.(21a). The earlier transient period directly yields permeability and Skin, using an estimated lateral effective length equivalent to the drilled length

(verified again by a fractured well model match), and confirming the full lateral to be contributing to flow. The later data match in Blasingame curve yields an estimate of the drainage area size and the OGIP, based on the well established PSS trend. This estimate is confidently supported by the Flowing Material Balance plot Fig.(21b), as an independent and highly reliable technique within the RTA suite of tools. In fact, the estimate of gas reserves using RTA under appropriate conditions has become a standard tool for reserve booking in the gas industry worldwide. 

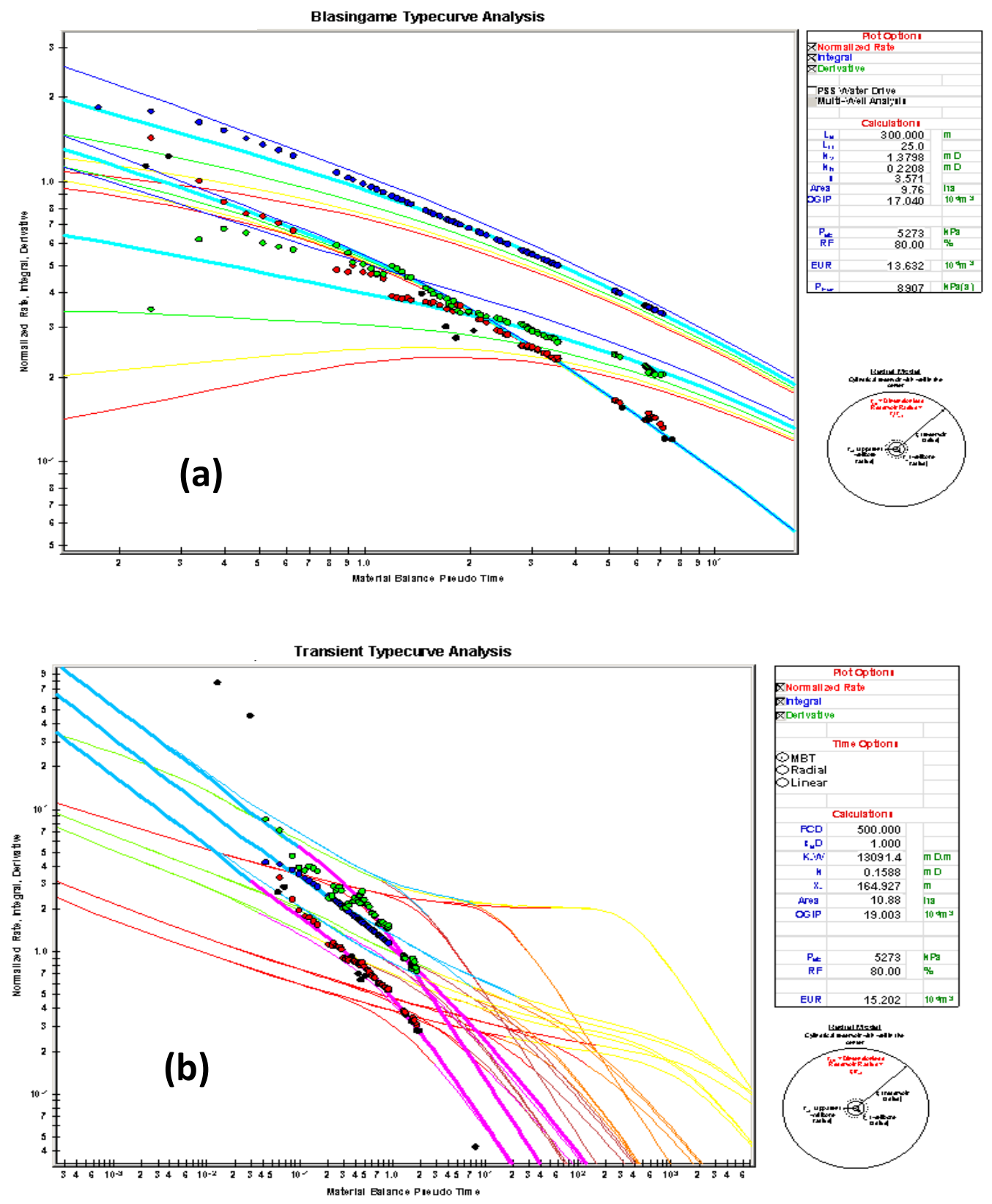

Fig.(20) RTA: Field Example of a Well in Transient Mode 


\section{Journal Of Petoleum Research \& Studies}
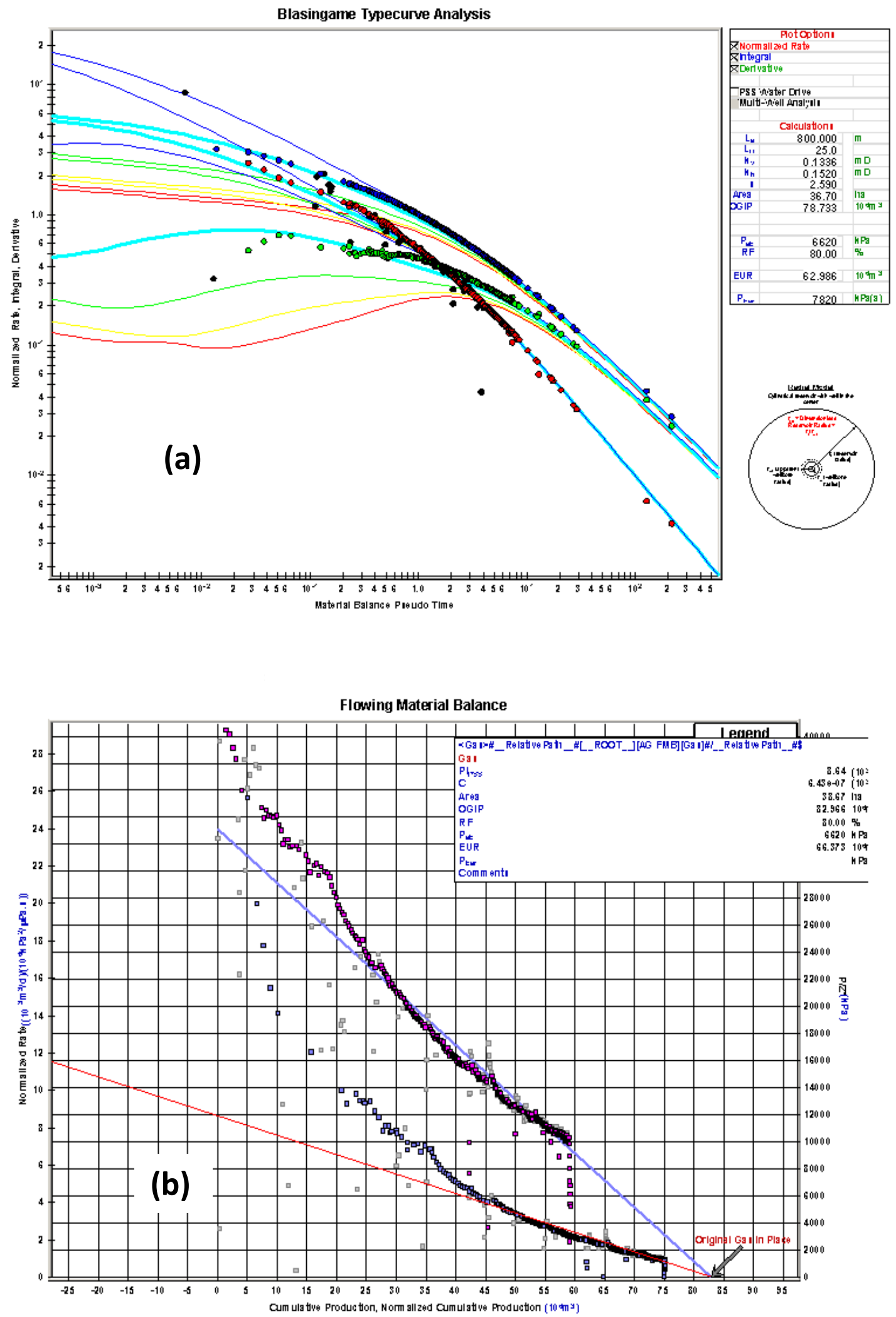

Fig.(21) RTA: Field Example of a Well in PSS Mode 


\section{Case History 2}

\section{The Bouri field offshore}

Libya was developed by constructing two Drilling and Production platforms (DP-3 and DP-4) in the Mediterranean Sea, starting production in 1988, with the last development well drilled in 1992. Out of 55 total, 7 wells were drilled as horizontals, 2 verticals, and the rest as slanted wells with up to $65^{\circ}$. Fig.(22) shows the field's map and well locations ${ }^{(10)}$.

The lithology of Metlaoui formation is dominated by Nummulitic limestone of good petrophysical properties. The reservoir comprises $100 \mathrm{~m}$ of oil, overlaid by an extended primary gas cap and underlain by an active aquifer, resulting in a combined drive mechanism of gas and water expansion Fig.(23) . Production performance is affected also by many faults that cut the structure, more dominantly in Sector-3 (DP3 area), with an associated network system of fractures and microfractures.

This discussion summarizes the performance of wells from production start up till 1996, when a further development stage was initiated by adding few more wells. The main objective initially put for the horizontal wells was to produce oil at an efficient rate by maintaining low drawdown to minimize the gas coning tendency. Geologically, subunit U2a of the Metlaoui formation was the main target in Sector-4 (DP-4 area), with an average thickness of $26 \mathrm{~m}$ and excellent lateral homogeneity, holding some $20 \%$ of the OOIP. It was the target of four horizontal wells in Sector-4. Above U2a in the stack is subunit $\mathrm{U} 2 \mathrm{~b}$, which consists of poor quality compact limestone of 6-9m thickness, 
forming a presumed natural barrier to gas. The uppermost subunit U2c has fairly good quality and wider lateral expansion over the whole development area. This unit was the target of the two horizontals in Sector-3, and one in Sector-4. A thick zone of low porosity that lies directly below U2a was expected to hamper the water advance.

The Sector-4 five horizontals were directly positioned below the gas cap at a stand off averaging $48 \mathrm{~m}$ from GOC, while the two HWS in Sector-3 lay at the edge of the gas cap at $60 \mathrm{~m}$ stand off, due to the area faulting. The lateral lengths represent the technology level at the time of drilling the wells with limited 'extended reach', and range between 215 and $610 \mathrm{~m}$. The wells were completed with 5in. liner (3 wells), 7in. liner (3 wells), and one well left as open hole. All the wells were acid stimulated via coiled tubing, and production logs run to validate the production profile, except for the open hole well.

Some theoretical calculations considered the good vertical conductivity from cores and pressure transient analyses Fig.(24), and showed that the critical rate for gas coning is in the low range of $35-50 \mathrm{~m}^{3} / \mathrm{d}$ per well, even when neglecting the fracturing effect. The HWS were initiated by rates ranging 240-500 $\mathrm{m}^{3} / \mathrm{d}$, which explains the early free gas production in many wells. It also indicates that tolerating a high gas production was necessary to maintain an economic field rate.

The performance of HWS was evaluated versus a group of conventional wells (CWS) that are completed mostly in the same subunits, i.e. U2a in Sector-4 and $\mathrm{U} 2 \mathrm{c}$ in Sector-3, and are located nearest to the HWS. The CWS 
group comprises eight wells in Sector-4 and five in Sector-3, perforated over intervals ranging from $23 \mathrm{~m}$ to $40 \mathrm{~m}$. The initial productivity comparison Fig.(25)

is showing the more consistent average of HWS in Sector-4 to be about double that of CWS.

The long term (1989-1996) performance of the wells is more indicative. In terms of cumulative oil production, HWS have produced $12 \%$ of the field's production, increasing to $16 \%$ in Sector-4. Fig.(26) shows the superior performance of the HWS, particularly in Sector-4. The smaller production in two wells (B4-09H, B3-19H) is due to an early choking down to reduce free gas rates. At the end of the studied period, three wells in Sector-4 have the highest oil rate in the field, and the least decline rate. The other parameter to consider is the gas production, expressed here as the cumulative produced gas-tooil ratio. The comparison shows that HWS in Sector-4 fall in the middle between the high gas producers of CWS below the gas cap, and the low gas producers at the edge of the Gas Cap, especially on the southern flank, where the aquifer pressure support is highest. The high gas rate in Sector-3 is due to the more fracturing in the area. 


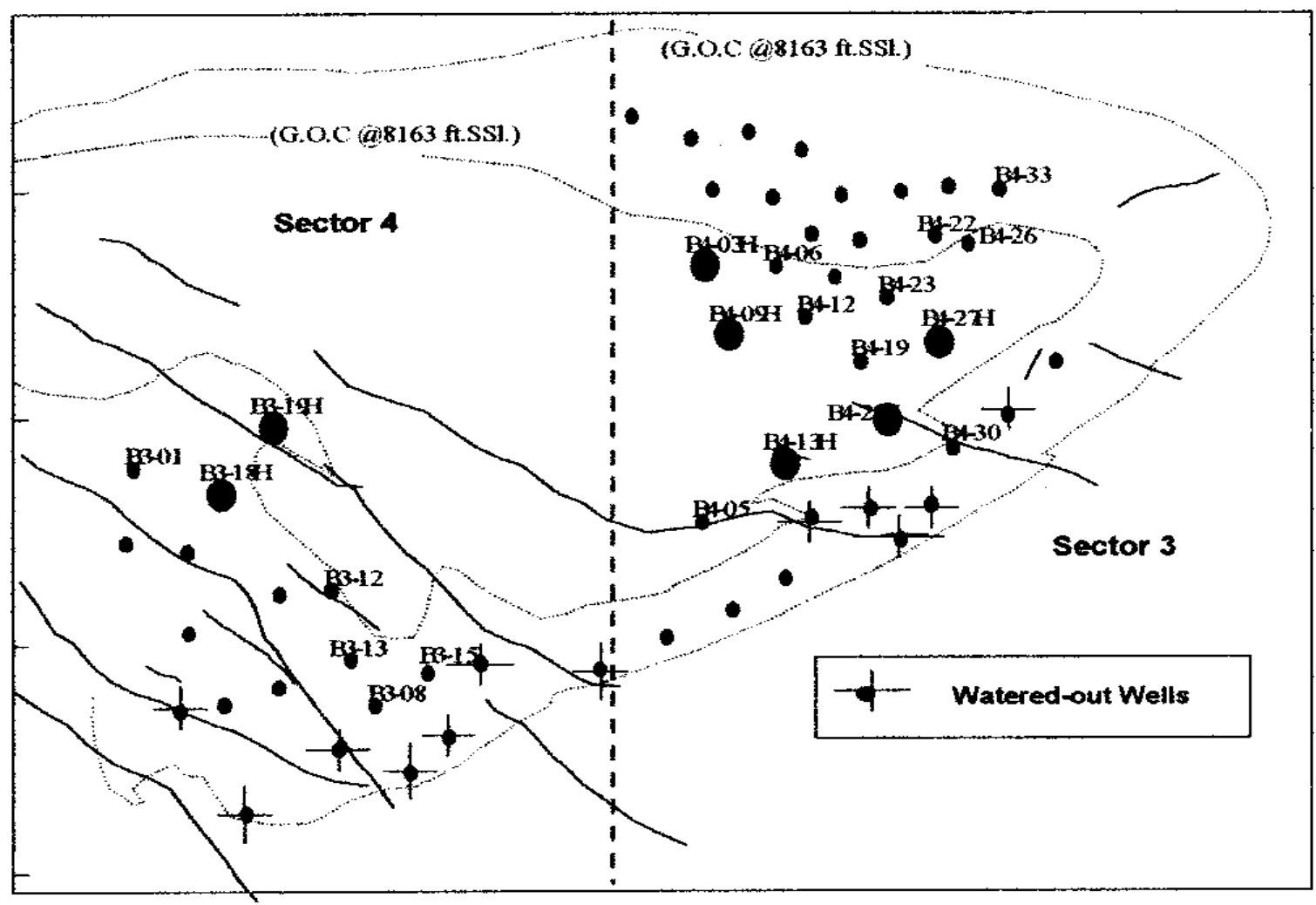

Fig.(22) Bouri Field, Structure and Well Locations, HWS as big circles (Ref-10)

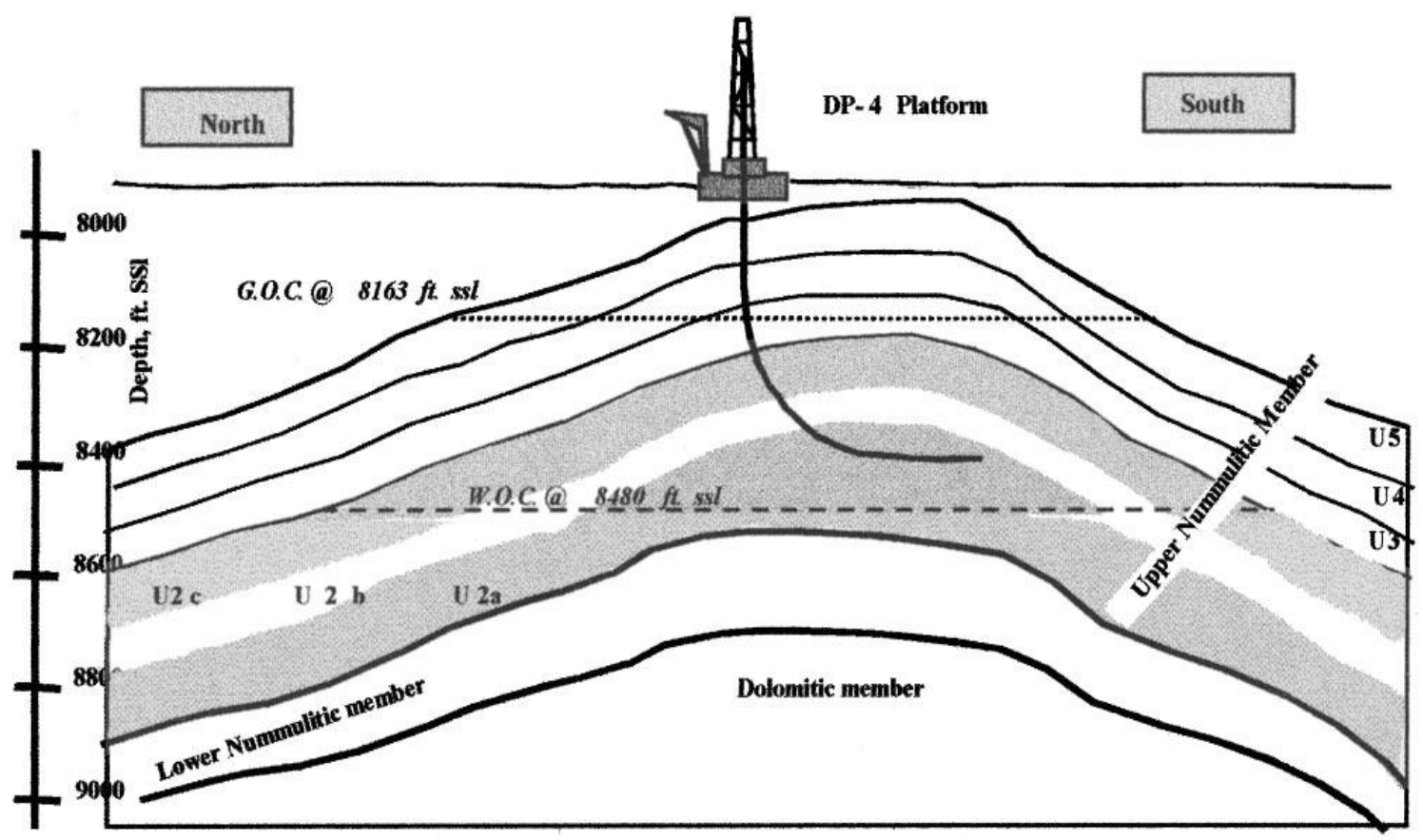

Fig.(23) Bouri Field, X-Section showing the Oil Column and Fluid Contacts (Ref-10)

$1^{\text {st }}$ Iraq Oil \& Gas Conference ( $1^{\mathrm{ST}}$ IOGC) 


\section{Journal Of Petoleum Research \& Studies}

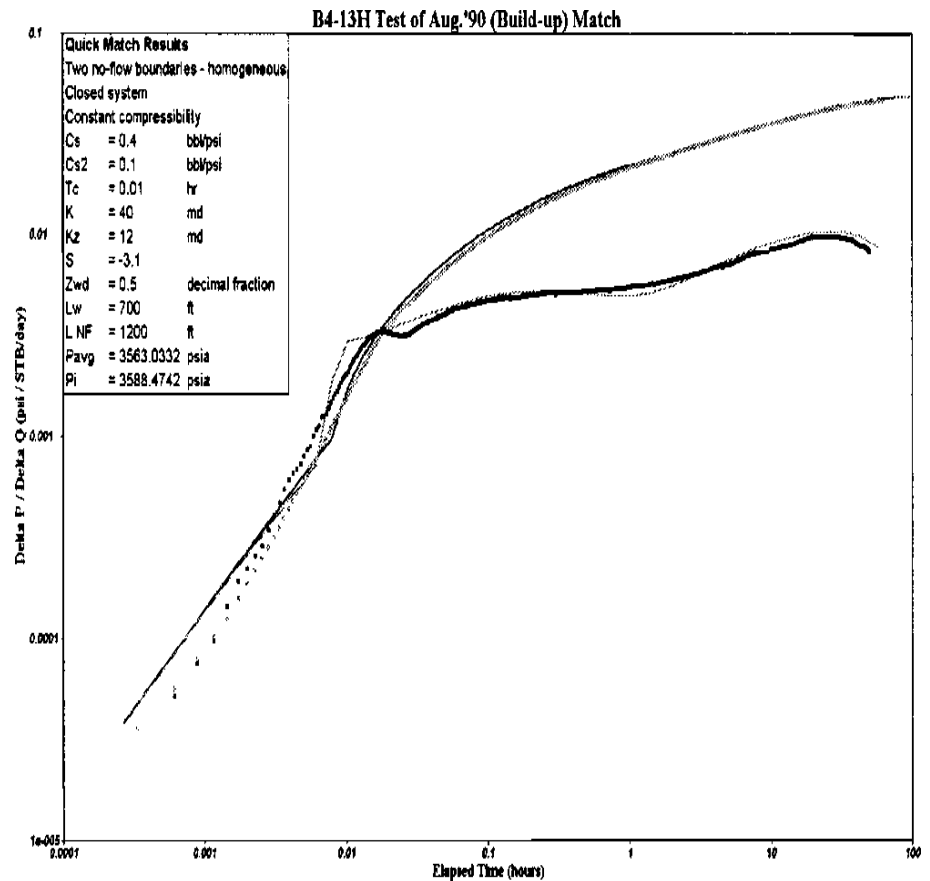

Fig.(24) Bouri Field, PTA of a Typical Horizontal Well (Ref-10)
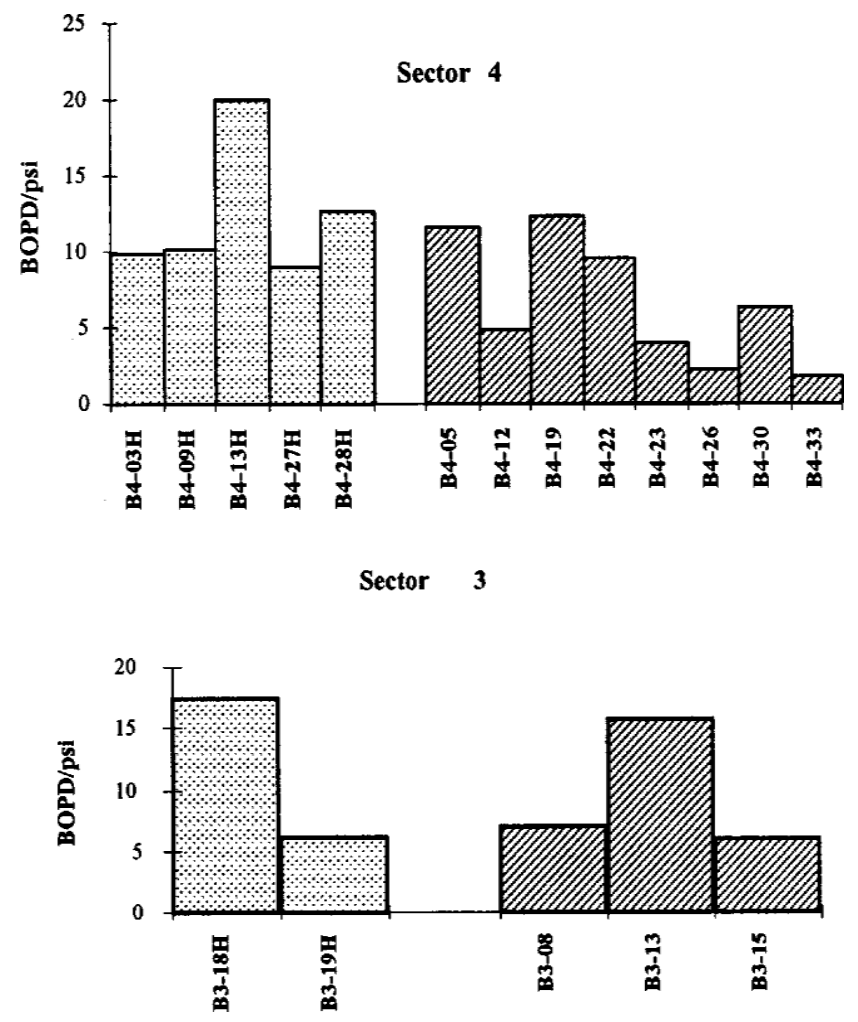

Fig.(25) Bouri Field, Initial Productivity Index Comparison 
Journal Of Petoleum Research \& Studies
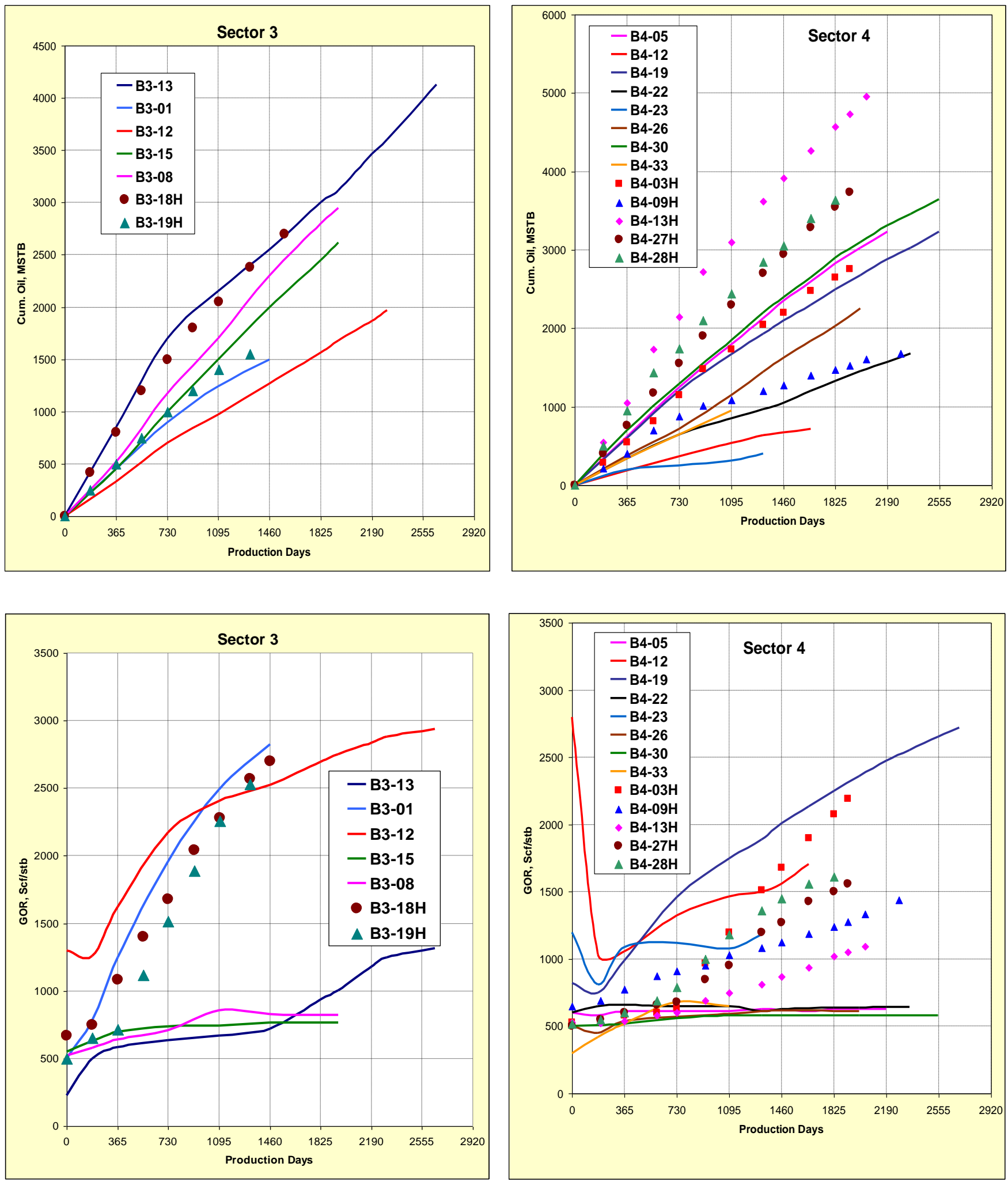

Fig.(26) Bouri Field, Performance Comparison of HWS

$1^{\text {st }}$ Iraq Oil \& Gas Conference ( $1^{\mathrm{ST}}$ IOGC) 
Advanced

And

Special

Applications Of Hws

The development of

drilling and completion technologies, the increased demand for energy resources, and the advances in the oil and gas enhanced recovery techniques have opened the gate to the development of reservoirs under increasingly challenging conditions and the implementation of several variations and combinations in horizontal well technology. Some of these are shown here, highlighting the application and briefing on some reservoir related issues.

\section{i- Multi-lateral Wells (MLWS) and Drain Holes:}

This topic covers applications whereas more than one lateral is flowing to the wellhead via a main wellbore. The branched laterals may be classified in two broad categories:

a) those drilled as part of the well construction together with the main wellbore, usually having long or medium radius laterals,

b) those drilled later as re-entry and intervention action, usually as short-radius laterals. As used here, a Drainhole refers to this second type.

MLWS were first used in Russia, in Siberia and few other areas, but the technology picked up in North America in the 1980's. The modern multi-lateral technology took its shape in the 1990's, with the introduction of the 'junction' concept for the type of hydraulic connection of branches to the main wellbore, and the pertinent classification accordingly into complexity levels 1-6. Many 
shapes and combinations have been applied Fig.(27), while many

Thousands of wells were registered worldwide as multilaterals in more than 30 countries.

The development of North Sea fields has set many landmarks in advancing the application of this technology. A good example is Troll field, offshore Norway, where MLWS played an essential role in achieving an efficient oil recovery, laying more than $550 \mathrm{~km}$ of horizontal hole on 130 wells within the reservoir pay zone, in a formation having a thin oil column of $4-27 \mathrm{~m}$ overlaid by a huge gas cap. In one case, the well covered 13,542m of reservoir Fig.(28) through five laterals. Well control and monitoring was made viable by integrating smart well technologies ${ }^{(11)}$.

In the Arabian Gulf area, a major operator has introduced the concepts of Extended Reservoir Contact (ERC) and Maximum Reservoir Contact (MRC). The latter is demonstrating wells that exceed $5 \mathrm{~km}$ of reservoir aggregate extension $^{(12)}$. The most common types used to achieve this target are the Fishbone and the Fork, and combination of both Fig.(29). The development of Shaybah Field in Saudi Arabia ${ }^{(12-14)}$ and Saih Rawl in $\operatorname{Oman}^{(15)}$ are good demonstration examples. In one reported case an MRC well of 12.3 $\mathrm{km}$ was achieved, enhancing the productivity of the well, and recovering three times oil volume of a corresponding $1.0 \mathrm{~km}$ reservoir contact well Fig.(30) . The reported corresponding reduction in net cost was $65 \%$.

Drainholes are laterals drilled from existing wells. Due to the loose use of terminology, all laterals are sometimes called drainholes in the literature. 
Addition of these drainholes can be thought of as a remedial action to improve oil recovery, especially valuable in mature fields and wells shut-in for increased water production. It is also useful for accessing stranded and by-passed oil in mature water,floods. With advances in coiled tubing technology, its use to drill extended reach drainholes ${ }^{(17)}$ in existing wells (verticals and horizontals) is now considered routine.

With all its benefits, it is obvious that these wells face many complexities in terms of production allocation, downhole pressure recording, well testing, and production logging, among others. It is usually required to implement advanced technologies such as smart completions and fiber optics for optimum reservoir monitoring.

\section{ii- Steam-Assisted Gravity Drainage (SAGD)Wells:}

This technology was developed in Western Canada (Alberta) in mid 1980's. Early field applications started in the 1990's but has commercially boosted since 2001 with remarkable success, achieving oil rates of more than $50.010^{3} \mathrm{~m}^{3} / \mathrm{d}$ in Alberta in $2010^{(18)}$. The objective is the thermal extraction of oil from deep bitumen deposits, as an improvement on the conventional Cycling Steam Stimulation (CSS) scheme Fig.(31) . The more typical application is for unconsolidated sands with bitumen viscosity exceeding $1.010^{6} \mathrm{cp}$.

The process utilizes twin parallel horizontal wells, typically 500$1000 \mathrm{~m}$ long each and $5 \mathrm{~m}$ vertically separated, targeting the bottom part of the bitumen column Fig.(32) . The upper well is the injector, whereas high pressure 
steam is pumped to transfer heat to the bitumen to reduce its viscosity in the "Steam Chamber", down to the point of triggering flow. By gravity segregation, the flowing heavy oil is driven to the lower well to be produced (pump lifted) to the surface. The mechanism is reported to achieve up to $60 \%$ of oil recovery efficiency in the contacted bitumen volume.

From reservoir engineering perspective, the involved physics are significantly different than that of traditional flow in porous media, being largely controlled by complex thermodynamical and geomechanical processes.

A main disadvantage of this technology is the high volumes of steam in use. Large amounts of water, together with high fuel consumption, are required to generate the steam for injection. On the production side, large amounts of water production should also be handled.

\section{iii- Multi-Fractured Horizontal Wells (MFHWS):}

This technology was developed in the past decade to make feasible the exploitation of low productivity gas reservoirs. It was then extended to oil wells, with variable degree of success. The main target of the technology is the ultra-tight reservoirs down to $1.010^{-3} \mathrm{mD}$ in the case of gas, and less than $1 \mathrm{mD}$ in the case of oil. Shale gas wells are ideal examples for this application.

A horizontal well is drilled, and the completion process is typically carried out by running a slotted liner with external packers, in order to divide the wellbore into several isolated completion intervals. A hydraulic fracture is then opened in each completion interval Fig.(33), starting at the toe side. The number of fracs is 
typically 5-15, with reported cases of up to 40 fracs, and with spacing of $50-100 \mathrm{~m}$ being the more common practice.

The development of two big accumulations in the United States formed a turning point in the implementation of the technology to develop unconventional resources Fig.(34), whereas the hydrocarbon in both is contained in the shale source rock. For Gas, the Barnett Shale (northern Texas) is estimated to have over $27 \mathrm{TCF}$ of gas in place $\left(765.010^{9} \mathrm{~m}^{3}\right)$. It became commercially feasible after 2002 through the intensive use of MFHWS. On the oil side, the development of Bakken reserves is a landmark in extracting oil from tight shales. The accumulation was estimated to have some 4 Billion barrels (635.0 $10^{6} \mathrm{~m}^{3}$ ) of reserves. Although the discovery of the field dates back to 1951, a big oil production boom was achieved only in 2008 when MFHWS were commercially introduced.

The cost per well is directly related to the number of fracs, which should be optimized by the design work prior to proceed to the completion process. The simulated impact of the number of fracs on well recovery for a tight gas reservoir case (permeability estimated at $0.03 \mathrm{mD}$ ) is shown in Fig.(35), indicating that in this case, exceeding 5 fracs is not economically justified.

With the increased number of applications in the industry, various engineering tools have recently become available to analyze the performance data from these wells. In particular, models for pressure transient analysis were published $^{(19)}$, and commercial software are now available that can handle the analyses. However, the analytical solutions published so 
far have many limitations and simplifying assumptions, with a basic deficit of being unable (or insufficient) to account for pressure interference between fracs. When more accurate results are desired, numerical models should be used. These models can be built to represent the fracs at their actual size and conductivity, using gridding techniques such as Local Grid Refinement. Fig.(36) shows the simulated pressure field around the well of Fig.(35) above, for the case of five fracs. Such models can be a useful tool for designing future MFHWS and predicting their performance. developments and the ambitious effort to boost oil and gas production, horizontal wells could be one of the key tools to achieve this target.

It is not the objective here to discuss in detail the application of HWS for specific fields. Instead, a broad description of environments favorable for this application is given. It is evident that the following characteristics are demonstrated in many existing Iraqi reservoirs, or could be encountered in future developments:

i- Low productivity reservoirs in Clastic formations, e.g. shaly sands.

ii- Low productivity reservoirs in Carbonate formations, particularly with high heterogeneity and lithofacies variation.

iii- Low API gravity oil reservoirs where viscosity prospect of facilitating field 
is a significant factor of the low productivity.

iv- Multi-layered reservoirs, whereas thin sand bodies are separated by shale streaks.

v- Pools with active bottom water drive, where water coning is a main cause for well shut-ins.

vi- Pools with active gas cap, where gas coning is a major production problem.

vii- Mature waterflood fields with potential to enhance recovery by tapping unswept oil, and/or tapping stranded oil due to heterogeneity.

viii- Reservoirs divided into fault blocks, where the faults form a high degree of hydraulic isolation. ix- Revival of shut-in wells in mature fields via re-entry and Drainhole technology, especially water production shut-ins.

x- Regions where well locations are environmentally sensitive, like oil fields in populated areas.

xi- Gas reservoirs in newly planned developments under low productivity conditions could be a potential for HWS or MFHWS technologies.

xii- Cost sensitive projects whereas reducing the well count is vital.

xiii- Future heavy oil fields could be candidates for SAGD technology. 


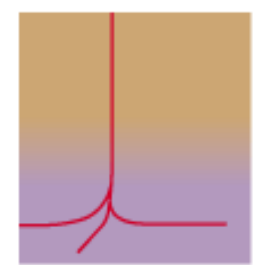

Multibranched

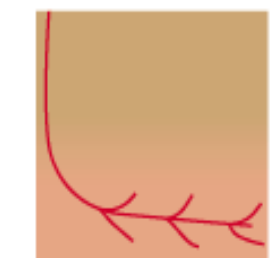

Laterals into horizontal hole

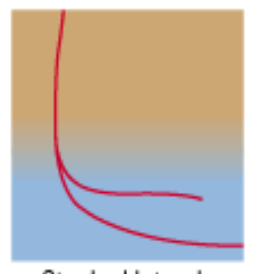

Stacked laterals

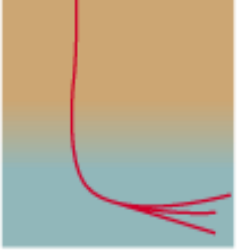

Forked

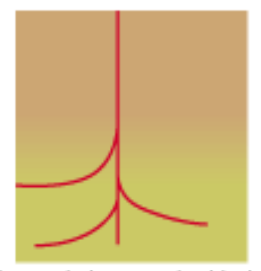

Laterals into vertical hole

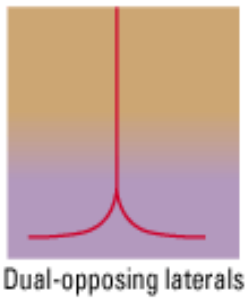

Fig.(27) Example Variations of MLWS (Ref-16)

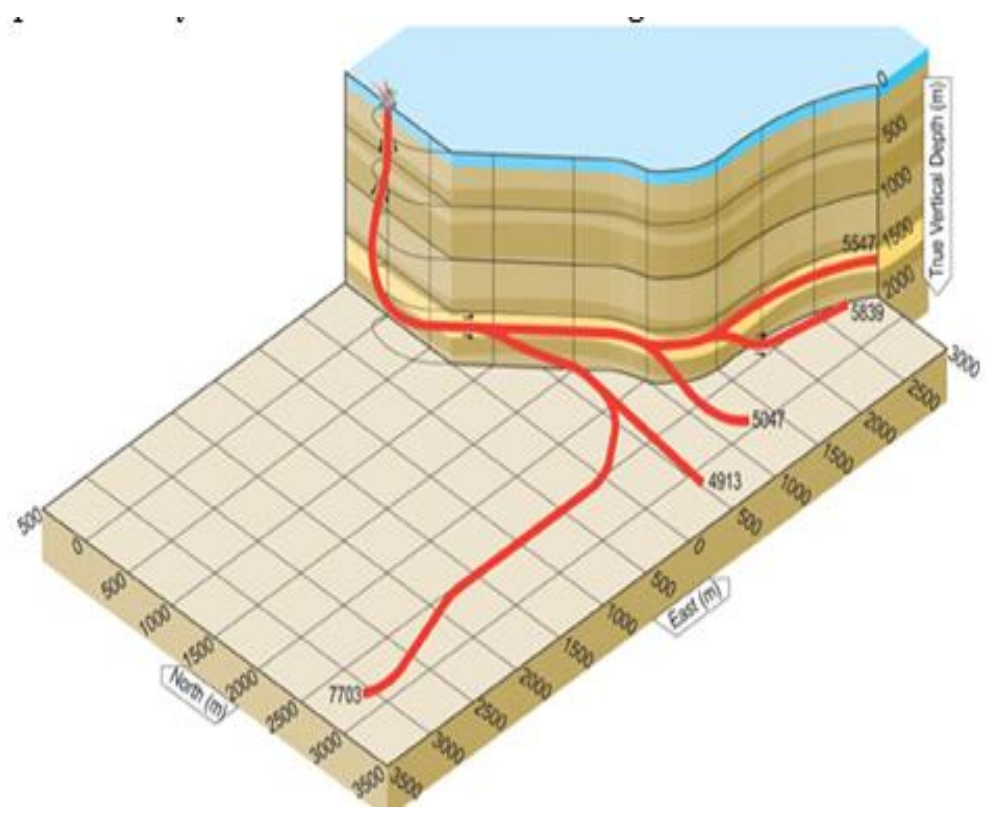

Fig.(28) Troll Field "Starfish" Well (Ref-11) 


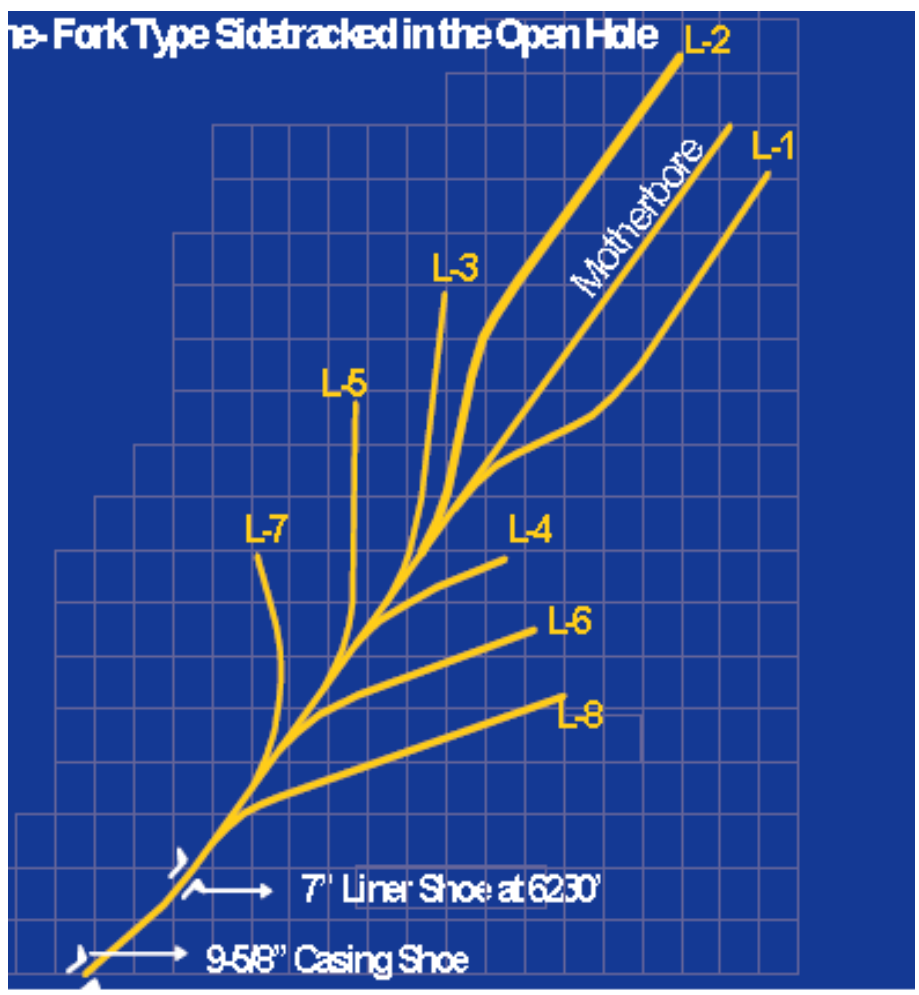

Fig.(29) Example of Maximum Reservoir Contact (MRC) well, Combining Fork and Fishbone Types (Ref-13)

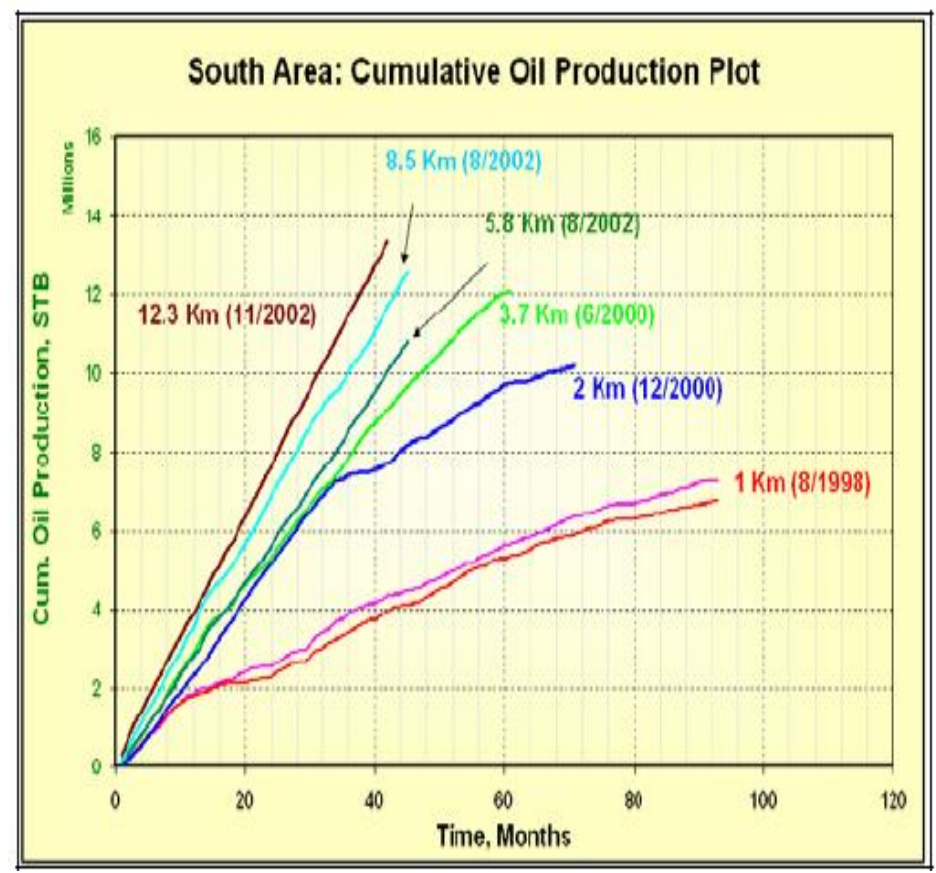

Fig.(30) Improvement in Recovery on Maximizing Reservoir Contact (Ref-14) 


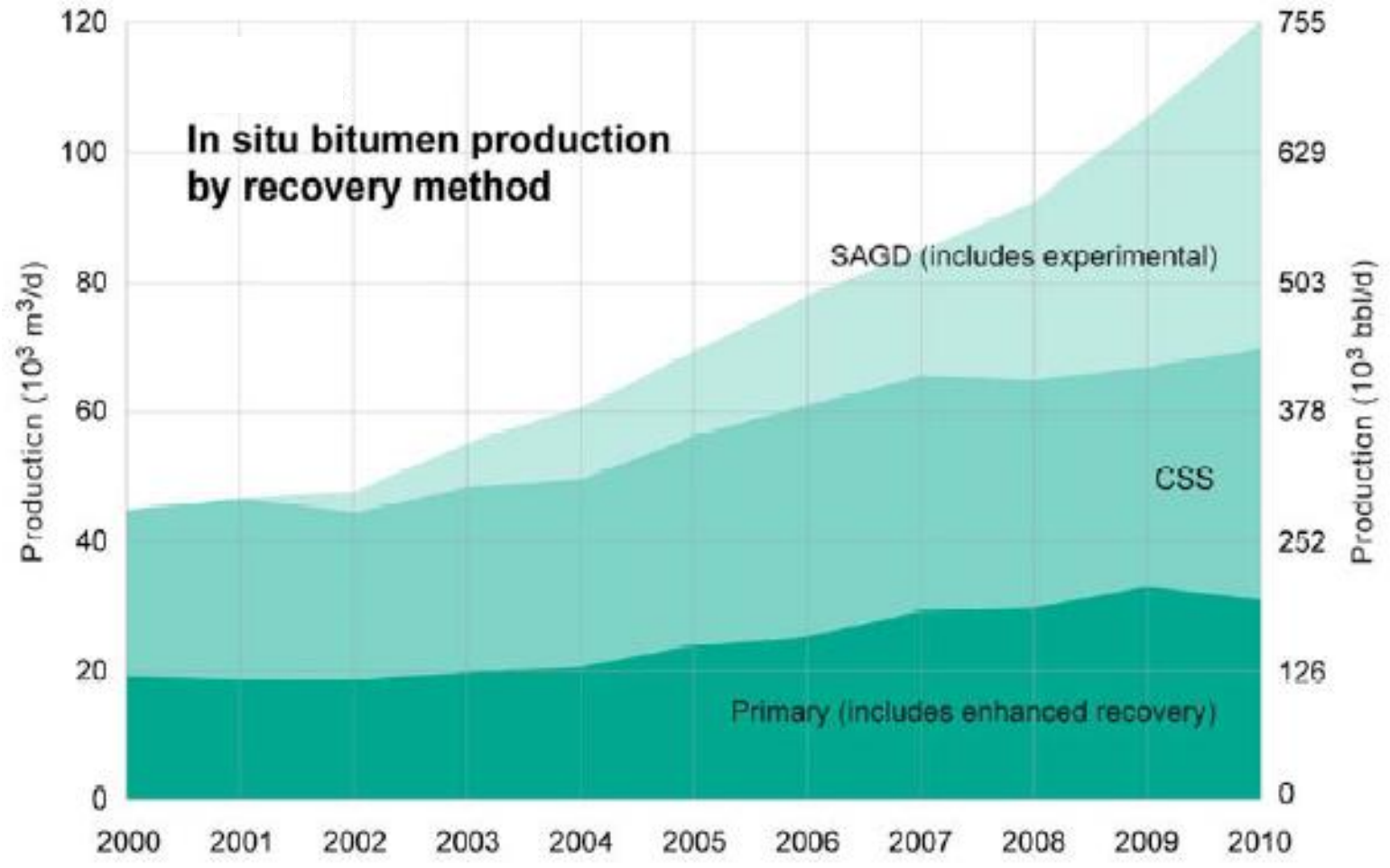

Fig.(31) Impact of SAGD on Oil Production in Alberta, Canada (Ref. 18)

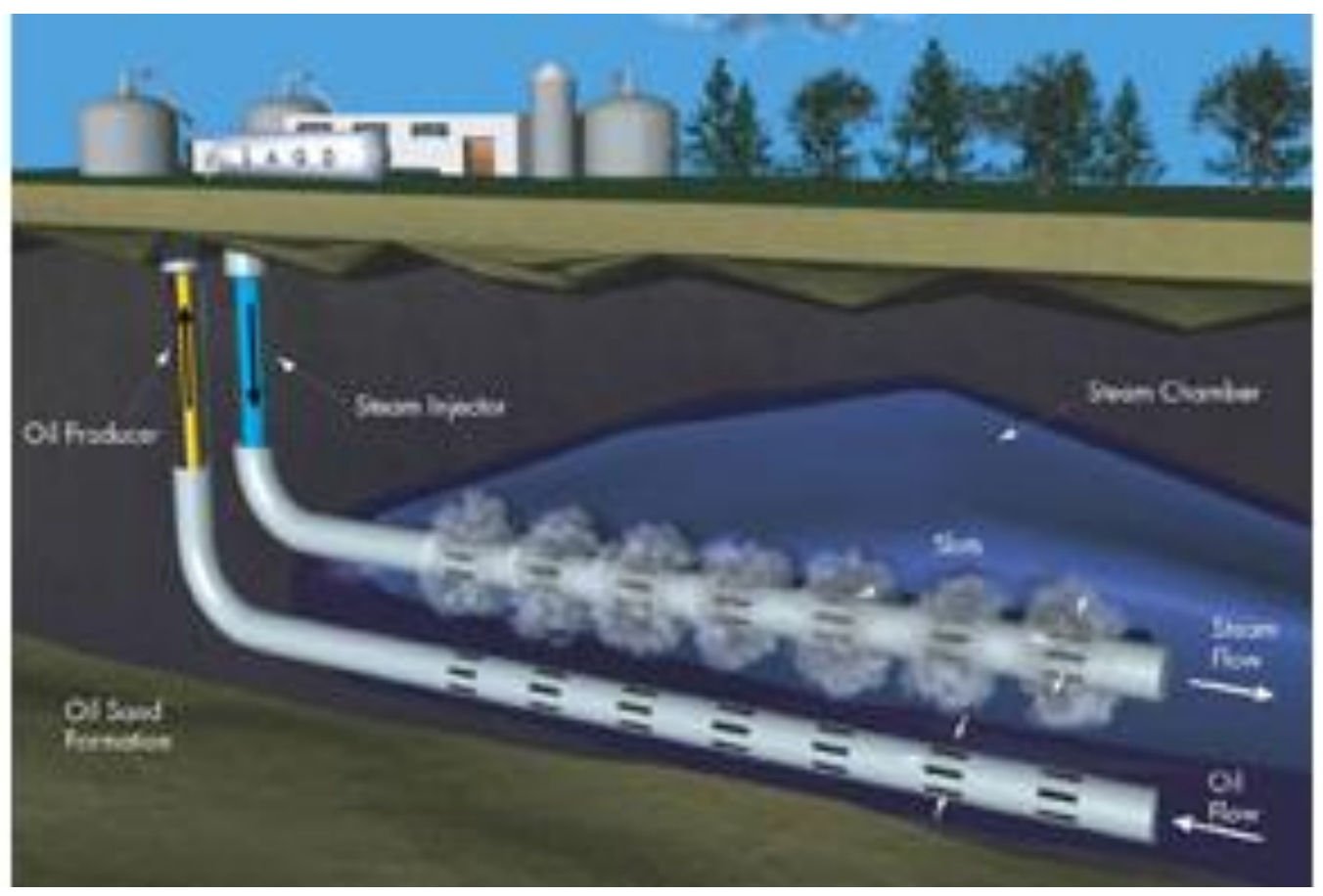

Fig.(32) Schematic of SAGD Process 


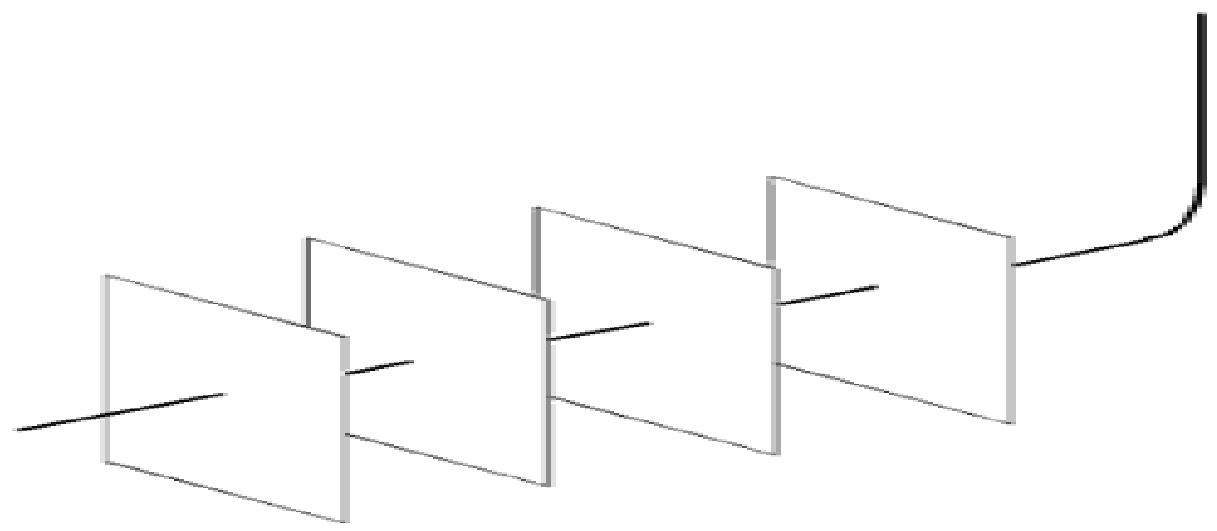

Fig.(33) Schematic of a Multi-Frac Horizontal Well (MFHW) Layout

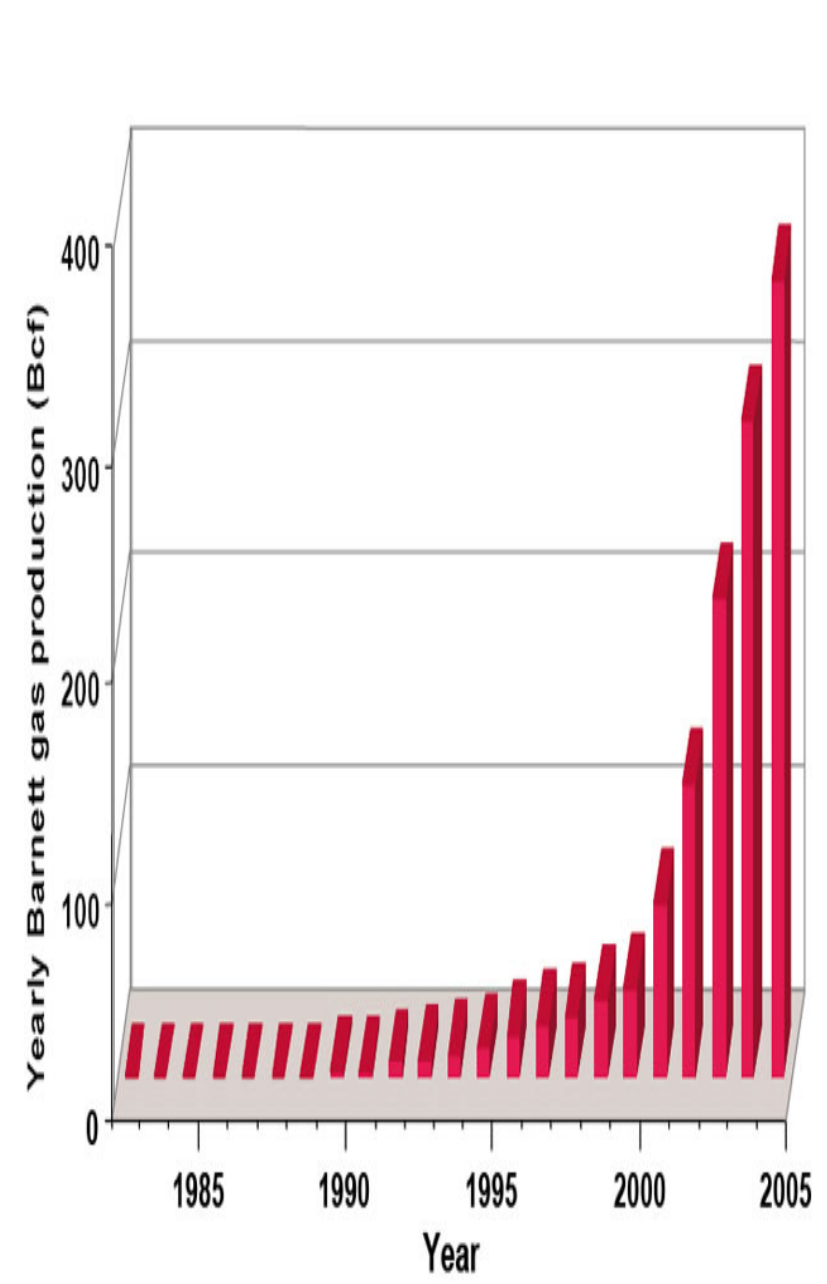

BAKKEN Production History (Montana and North Dakota)

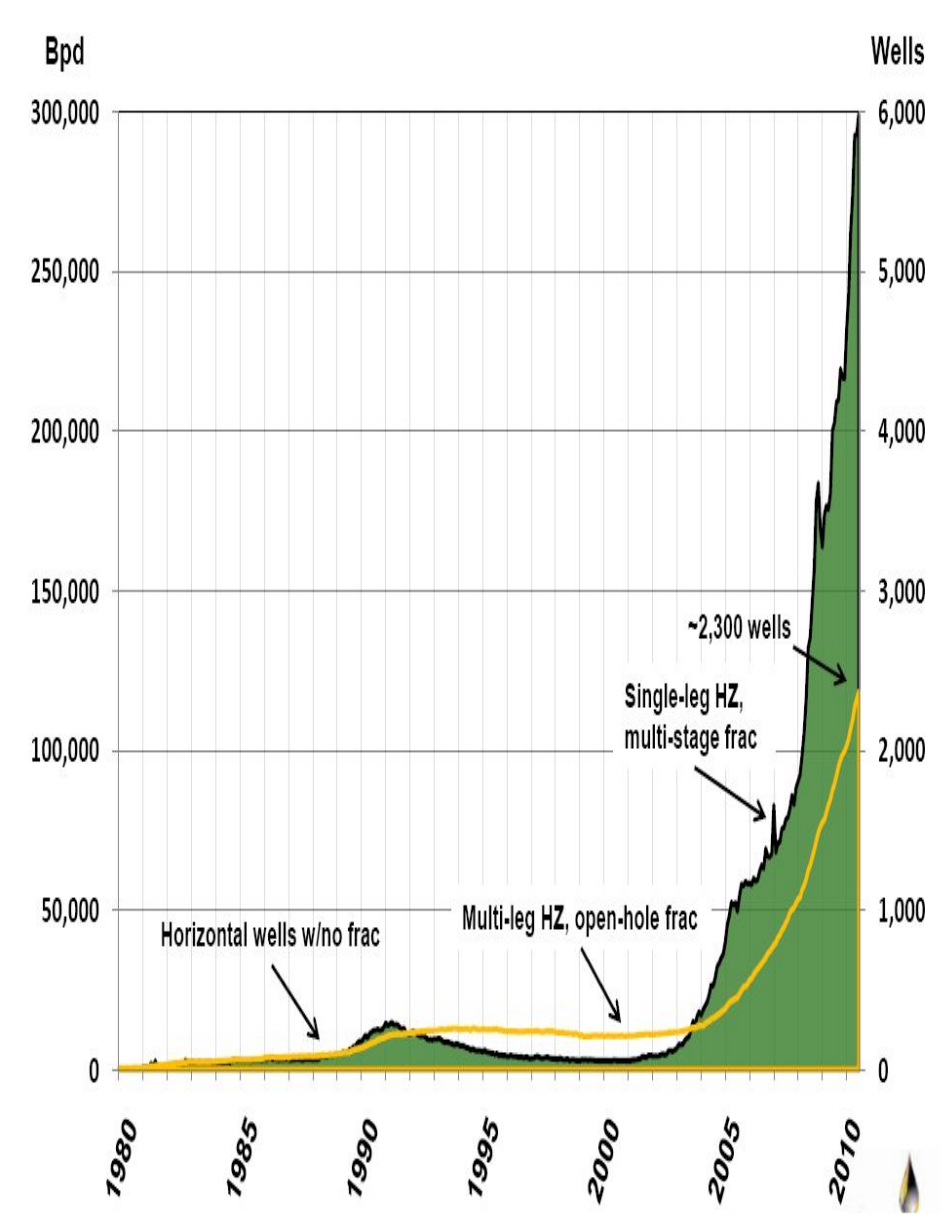

Fig.(34) Impact of MFHWS Development on Production of Barnett Shale Gas (left) and Bakken Shale Oil (right) 


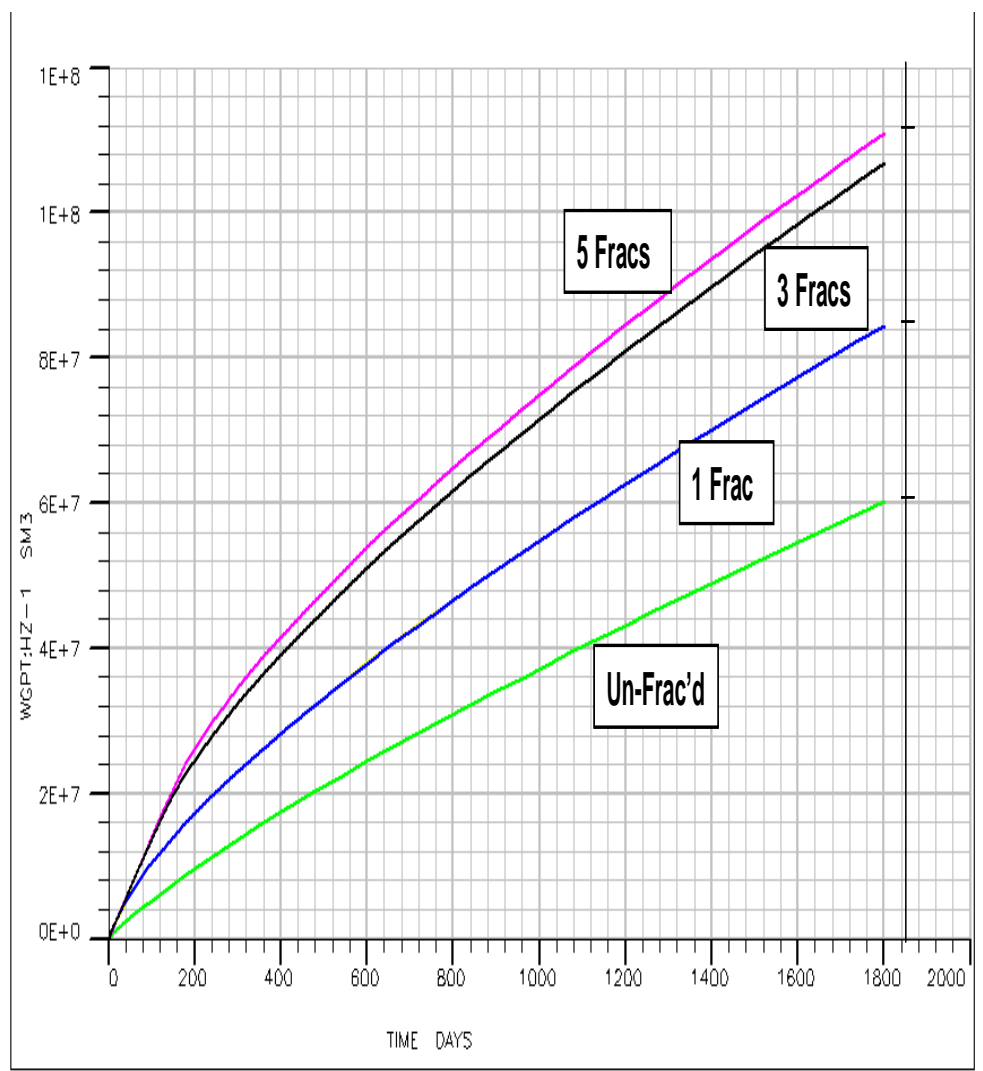

Fig.(35) Impact of number of Fracson Gas Production, simulated

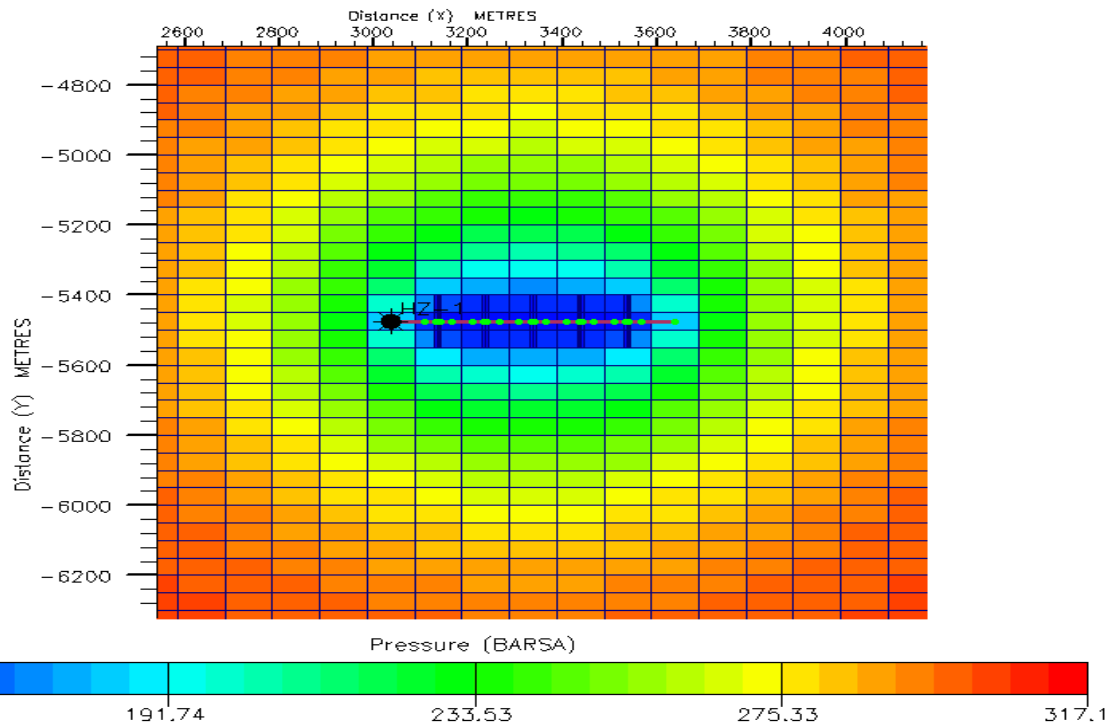

Fig.(36) Simulated Pressure Field around a MFHW

$1^{\text {st }}$ Iraq Oil \& Gas Conference $\left(1^{\mathrm{ST}}\right.$ IOGC) 


\section{Conclusions}

1- Horizontal wells have proved to be a valuable tool to increase productivity and improve recovery in a wide range of reservoir conditions worldwide.

2- Reducing production problems such as high gas and water rates in horizontal wells is a main advantage on the performance.

3- With the current advance in technology, there is practically no limit on the geometry (shape) of these wells, while the lateral extension is approaching that of many giant fields' dimensions.

4- Careful planning of horizontal wells involving the integration of robust geologic and reservoir models with relevant operational considerations can assure the success of field development.

5- Reservoir engineering tools are now available for the modeling and analysis of production and pressure data from all standard horizontal wells, while new tools are emerging in support of handling special applications like the multifractured horizontals.

6- Many conditions in Iraqi fields favor the application of the horizontal well technology for mature fields, heavy oils, new developments, and enhancement of ongoing developed fields.

7- Advanced technologies with horizontal wells have been proved successful for thermal extraction of heavy oil (SAGD) and efficient development

of 
unconventional (very tight) oil and gas fields (MFHWS), and can be evaluated for future applications in Iraqi fields.

\section{$\underline{\text { Recommendations }}$}

It is recommended to introduce the horizontal well technology to various Iraqi fields where the conditions are Appropriate. While the effort in the initial phase could focus on drilling and completion techniques, it is required to prepare the reservoir engineering basis (personnel, software, and hardware) for the different aspects of dealing with these wells in terms of monitoring, data acquisition, data analyses, and numerical modeling.

\section{Nomenclature}

B: Fluid Formation Volume

Factor, vol/vol

$\mathrm{C}_{\mathrm{t}}$ : Total Compressibility, $\mathrm{kPa}^{-1}$

H: Net Pay Thickness, m

$\mathbf{J}_{\mathbf{v}}$ : Productivity Index in Vertical

Wells, $\mathrm{m}^{3} / \mathrm{d} / \mathrm{kPa}$

$\mathbf{J}_{\mathbf{h}}$ : Productivity Index in

Horizontal Wells, $\mathrm{m}^{3} / \mathrm{d} / \mathrm{kPa}$

$\mathbf{K}_{\mathrm{v}}, \mathbf{K}_{\mathrm{h}}$ : Vertical and Horizontal

Permeability, mD

$\mathbf{L}_{\mathbf{h}}$ : Horizontal Well Length, $\mathrm{m}$

q: Flow Rate, $\mathrm{m}^{3} / \mathrm{d}$

$\mathbf{r}_{\mathrm{w}}, \mathrm{r}_{\mathrm{e}}$ : Well and Drainage Area

Radius, $m$

$\mathbf{X}_{\mathbf{f}}$ : Fracture Half-Length, $\mathrm{m}$

$\mu$ : Fluid Viscosity, cp

Ф: Porosity, fraction 


\section{$\underline{\text { Abbreviations }}$}

$\mathrm{F}_{\text {or }}$ convenience, the

following abbreviations are used in this paper. They are not claimed to be standards, though many are formally allowed by Society of Petroleum Engineers (SPE), and are being commonly used in the oil and gas literature.

BHFP: Bottom-Hole Flowing

Pressure

BHIP: Bottom-Hole Injection

Pressure

CWS: Conventional Wells

(verticals and Deviated)

ERC, MRC: Extended and

Maximum Reservoir Contact

GOC: Gas to Oil Contact

Fracs: Fractures

MFHWS: Multi-Fractured

Horizontal Wells
MLWS: Multi-Lateral Wells

HW(S): Horizontal Well, Wells

MD: Measured Depth

OGIP: Original Gas In-Place

OOIP: Original Oil In-Place

OWC: Oil to Water Contact

PSS: Pseudo-Steady State

PTA: Pressure Transient Analysis

RTA: Rate Transient Analysis

TVD: True Vertical Depth

VW(S): Vertical Well, Wells

WBS: Wellbore Storage 


\section{$\underline{\text { References }}$}

1. Joshi, SD, (1991) "Horizontal Well Technology", PennWell Publishing Co.

2. Stevens, DG, (2000), et al, "Predicting Multiple Thermal Fractures in Horizontal Injection Wells; Coupling of a Wellbore and a Reservoir Simulator", Paper SPE 59354.

3. Hammou, NE, (2009), et al, "Effective Reservoir Management Through Integration of Formation Pressure While Drilling, Well Log and Seismic Data in the White Rose, Offshore Newfoundland, Canada", Paper SPE 125355 Paper,

4. Canada-Newfoundland and Labrador Offshore Petroleum Board (http://www.cnlopb.nl.ca/)

5. Bourdet, DP, (1983), et al, “A new Set of Type Curves Simplifies Well Test Analysis", World Oil

6. Lichtenberger, GJ, (1994) "Data Acquisition and Interpretation of Horizontal Well Pressure Transient Tests”, Paper SPE 25922.

7. Theory and Equations, FAST Welltest Advanced PTA, http://www.fekete.com

8. Agarwal, RG, (1999), et al, "Analyzing Well Production Data Using Combined Type Curve and Decline Curve Concepts", Paper 7916 .

9. Blasingame, TA, (1991), et al, "Decline Curve Analysis form Variable Pressure Drop/Variable Flowrate Systems”, Paper SPE 21513.

10. Jafar (Zalzala), AS, (2000), et al, "Discussion and Comparison of Horizontal-Well Performance in Bouri Field”, Paper SPE 68321.

11. Henriksen, KH, (2006) et al, "Case Study: The Application of Inflow Control Devices in the Troll Field", Paper SPE 100308. 
12.Saleri, NG, ( 2003) et al, "SHAYBAH-220: A Maximum Reservoir Contact (MRC) Well and its Implications for Developing Tight Faces Reservoirs“, Paper SPE 81487.

13.Dossary, AS,( 2003), et al, "Challenges and Achievements o0f Drilling Maximum Reservoir Contact Wells in Shaybah Field”, Paper SPE 85307. 14.Salamy, SP,( 2007), et al, "MRC Wells Performance Update, Shaybah Field, Saudi Arabia”, Paper SPE 105141.

15.Senger, JC,( 2001), et al, " Producing the Ultimate from the Saih Rawl Shuaiba Reservoir", Paper SPE 68222.

16.Multilateral, http://www.glossary.oilfield.slb.com

17.Leising, LJ,( 1997), et al, "Extending the Reach of Coiled Tubing Drilling (Thrusters, Equalizers, and Tractors”, Paper SPE 37656.

18.“Alberta's Energy Reserves 2010 and Supply/Demand Outlook 20112020”, Energy Resources Conservation Board (ERCB), ST98-2011

19.Ozkan, E, (2009) , et al, "Comparison of Fractured Horizontal-Well Performance in Conventional and Unconventional Reservoirs", Paper SPE 121290. 